\section{BIBLIOGRAPHY AND CURRENT STATUS OF $K, L$, AND HIGHER SHELL FLUORESCENCE YIELDS FOR COMPUTATIONS OF PHOTON ENERGY-ABSORPTION COEFFICIENTS}

John H. Hubbell

U.S. DEPARTMENT OF COMMERCE Nathonal Institute of Standards and Tochnology

Contor for Radistlon reserch Calthershurs, MD 20899
U.S. DEPARTMENT OF COMMEREE Wobert A. Mosbacher, Secrotary MATHONAL INSTTUTE OF STANDARDS AND TECHNOLOGY

Raymond C. Kammes, Actine DIrastor 
Niste

QC100

- US6

BIBLIOGRAPHY AND

100.89 .4144

1989

C.2

$K, L$, AND HIGHER SHELL

FLUORESCENCE YIELDS

FOR COMPUTATIONS

OF PHOTON

ENERGY-ABSORPTION

COEFFICIENTS

John H. Hubbell

U.S. DEFPATMENT OP COMMERCE

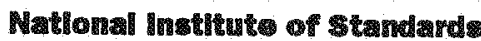

and Tochnologty

Canter for Radlatlon Dosearth

Cathorburg, MD 20899

Augurat 1989

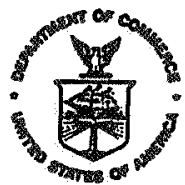

U.8. DEPATTMENT OF COMMERCE

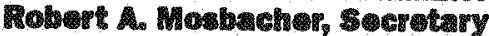
MATONA HMSTHUT: OF STANDARD: MND TECHMOLOQY

1. 


\title{
BIBLIOGRAPHY AND CURRENT STATUS OF $K, L$, AND HIGHER SHELL FLUORESCENCE YIELDS FOR COMPUTATIONS OF PHOTON ENERGY-ABSORPTION COEFFICIENTS
}

\author{
J. H. Hubbe 11 \\ 11830 Rocking Horse Road, Rockville, MD 20852 \\ ABSTRACT
}

This report reviews $x$-ray fluorescence yield experimental and theoretical information beyond that available in earlier extensive reviews by Fink et al., (1966), Bambynek et a1. (1972), and by Krause (1979). An annotated bibliography 1978-1988 is included. Tables and fits of the $K$ shell fluorescence yield $\omega_{K}$, and the average $L$ and $M$ shell fluorescence yields $\bar{\omega}_{L}$ and $\bar{\omega}_{M}$, for use in computing photon energy-absorption coefficients $\mu_{\mathrm{en}} / \rho$, are presented.

KEYWORDS: Auger effect; energy-absorption coefficient; fluorescence yield; ionization; photon; radiationless transitions; vacancies; $x$-ray.

\footnotetext{
PREPARED FOR: U. S. Department of Commerce, National Institute of Standards and Technology, in fulfillment of Contract No. 52SBNB9C5226, Phase One, COTR Dr. B. M. Coursey
} 


\section{BIBLIOGRAPHY AND CURRENT STATUS OF $K, L$, AND HIGHER SHELL FLUORESCENCE YIELDS FOR COMPUTATIONS OF PHOTON ENERGY ABSORPTION COEFFICIENTS}

TABLE OF CONTENTS

II. Application of Fluorescence Yield Data in Computing Mass Energy-Absorption Coefficients

III. K-Shell Fluorescence Yield $\omega_{K} \ldots \ldots \ldots \ldots \ldots \ldots \ldots \ldots \ldots \ldots \ldots \ldots$

IV. L-Shell Average Fluorescence Yield $\bar{\omega}_{L} \ldots \ldots \ldots \ldots \ldots \ldots \ldots$

V. M-Shell Average Fluorescence Vield $\bar{\omega}_{M} \ldots \ldots \ldots \ldots \ldots \ldots \ldots \ldots \ldots \ldots$

VI. $\mathrm{N}$ - and Higher-Shell Average Fluorescence Yields ............... 14

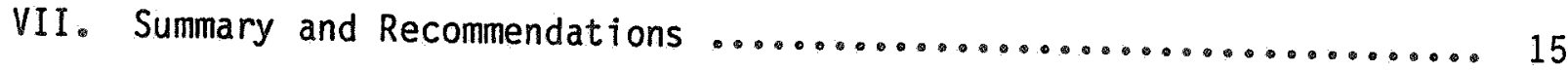

VIII. Annotated Bibliography of X-Ray Fluorescence Yield Measurements, Analysis, Fits, and Tables 1978-1988 ........... 17

IX. Additional Text References .......................... 27

X. Tables 1 to 4 : $\omega_{K}, \bar{\omega}_{L}, \bar{\omega}_{M}$, and Summary Table.............. 30 


\section{INTRODUCTION: DEFINITIONS, HISTORY}

Values of the fluorescence yield $\omega_{j}(z)$, where $i$ represents a given atomic electron sheli or subshell, of an atom with atomic number $Z$, are required in a variety of applications including atomic physics studies, $x$-ray fluorescence (XRF) surface chemical analysis, and dosimetric computations for health physics, cancer therapy, and industrial irradiation processing. The focus of this report will be on fluorescence yield information for the latter application, in particular the computation of the photon energy-absorption coefficient $\mu_{\text {en }} / \rho$.

An excellent description of the fluorescence yield given by Compton and Allison (35C001) is briefly paraphrased as follows. When an inner shell atomic electron is ejected from an atom as a result of a collision process involving a photon or other incoming projectile, a vacancy is created in that electron's pre-collision subshel1. For incoming photons, such processes could be the photoelectric effect, Compton collisions, and triplet production (electron-positron pair production in the field of the atomic electrons, by photons with energy in excess of $2.04 \mathrm{MeV}$ ). Associated with this inner-she11 vacancy is an excess of energy above the atom's ground state. The atom returns to its ground state, including filling the vacancy, by one two modes. In one mode a fluorescence (or characteristic) $x$-ray is emitted from the atom, with photon energy equal to the difference between the vacancy-site inner-shell energy level and the energy level of the particular outer shell which happens to supply the electron to fill the vacancy. In the other mode, no fluorescence $x$-ray is emitted, but instead the excess energy ejects an outer-shell electron from the atom (in addition to the ejected electron causing the original vacancy). This second ejected electron is known as an 
Auger electron, after the cloud chamber confirmation and explanation by Auger (25Au01, 25Au02) of earlier conjectures by Sadler (09Sa01) and Barkla (17Ba01) and observations by Wilson (23Wi01, 23Wi02).

In simplest terms, the fluorescence yield $\omega_{i}(Z)$ is

$$
\omega_{i}(Z)=f_{i}(Z) / v_{i}(Z)
$$

where $f_{i}(Z)$ is the average number of fluorescence (characteristic) $x$ rays emitted as a result of $v_{i}(Z)$ vacancies created in the $i^{\text {th }}$ shell or subshell. In reality the situation is quite complex due to the multiplicity of transitions of varying likelihood involving the participating inner and outer subshells, the details of which are described in the extensive reviews by, e.g., Fink et al. (66Fi01), Bambynek et al. (72Ba01), Krause (79Kr01), Mitchell and Barfoot (81Mi01), and Cohen (87C001). This report is an annex to, and not a replacement of, these earlier major reviews.

Compton and Allison (35C001) and some later authors, e.g.. Tertian and Claisse (82Te01) consider the Auger effect a two stage process in which the characteristic $x$ ray is first emitted but then reabsorbed by an outer electron shell in a photoeffect type process. However, other authors, such as N. A. Dyson (73Dy01), contend that the Auger effect must be a one stage process because of strong lines (such as the $K \rightarrow L_{1}$ transition) in the Auger spectra which are forbidden in radiative transitions.

The annotated bibliography in this report combines an automated search of Physics Abstracts with a manual search by Trehan and collaborators (89Tr01), and focuses on the time period 1978-1988 following the Krause (79Kr01) 1979 review article. Additional text references are listed separately following the annotated bibliography. 


\section{APPLICATION OF FLUORESCENCE YIELD DATA IN COMPUTING MASS ENERGY-} ABSORPTION COEFFICIENTS

The mass energy-absorption coefficient $\mu_{\mathrm{en}} / \mathrm{\rho}\left(\mathrm{cm}^{2} / \mathrm{g}\right.$ or $\mathrm{m}^{2} / \mathrm{kg}$, where $1 \mathrm{~cm}^{2} / \mathrm{g}=0.1 \mathrm{~m}^{2} / \mathrm{kg}$ ), a key parameter in computations of energy deposited in media subjected to photon irradiation, is defined (see, e.g., R. T. Berger (61Be01), Hubbell (77Hu01), Hubbell (82Hu01), and Higgins et al. (89Hi01)) as

$$
\mu_{\mathrm{en}} / \rho=(\mu / \rho) f
$$

In this expression, $f$ is the average fraction of the incident photon energy $E_{0}$ which does not leave the site of the primary collision in the form of secondary photon radiation (fluorescence, Compton scattered photons, annihilation radiation, bremsstrahlung, etc.). This fraction $f$ goes into kinetic energy of particles, particularly electrons, for dissipation locally in the medium via collision losses as ionization and excitation. Here $\mu / \rho$ is the total mass attenuation coefficient (see, e.g., Hubbell (69Hu01)) for a given incident photon energy $E_{0}$ in a given substance:

$$
\mu / \rho=\sigma_{\text {incoh }} / \rho+\sigma_{\text {coh }} / \rho+\tau / \rho+\kappa_{n} / \rho+\kappa_{e} / \rho+\sigma_{p h . n_{0}} / \rho
$$

in which the significant interaction components are incoherent (Compton) scattering $\sigma_{i n c o h} / \rho$, coherent (Rayleigh) scattering $\sigma_{\mathrm{coh}} / \rho$, atomic photoeffect $\tau / \rho$, electron-positron pair production in the field of the atomic nucleus $\kappa_{n} / \rho$, pair production in the field of the atomic electrons (triplet production) $k_{e} / \rho_{3}$ and photonuclear interactions $\left(e_{0} g_{0},(\gamma, n),(\gamma, 2 n),(\gamma, p)\right.$, $(\gamma$, fiss $)$, etc. $) \sigma_{p h . n_{0} / \rho \text {. }}$ 
In equations (2), (3), and (4) the units of $\mu / \rho$ and $\mu_{\mathrm{en}} / \rho$ have been customarily $\mathrm{cm}^{2} / \mathrm{g}$, as well as all of the term on the right hand side of eq (3) (e.g., $\sigma_{i n c o h} / p$ in $\left.\mathrm{cm}^{2} / \mathrm{g}\right)$. However, the preferred units for these quantities $\left(\mu / \rho, \mu_{\mathrm{en}} / \rho\right.$, etc. $)$ are in the SI base units $\mathrm{m}^{2} / \mathrm{kg}$ (where $1 \mathrm{~m}^{2} / \mathrm{kg}=$ $10 \mathrm{~cm}^{2} / \mathrm{g}$ ) as in the tables of Hubbell (82Hu01) and in ICRU Report 44 (89Ic01).

For computational purposes eq (2), using the information on the individual processes indicated in eq (3), becomes:

$$
\begin{aligned}
& \mu_{\text {en }} / \rho=(\mu / \rho) f=\left(\sigma_{\text {incoh }} / \rho\right) f_{\text {incoh }}+(\tau / \rho) f \\
& \tau+\left(\kappa_{n} / \rho\right) f_{\kappa_{n}} \\
&+\left(\kappa_{e} / \rho\right) f \\
& \kappa_{e}+\left(\sigma_{p h_{0} n_{0}} / \rho\right) f \\
& \sigma_{p h . n} .
\end{aligned}
$$

in which the $\sigma_{\mathrm{coh}} / \rho$ term in eq (3) is omitted because the coherent scattering process deposits negligible energy at the collision site. Also, in existing $\mu_{e n} / \rho$ tables, the photonuclear term $\left(\sigma_{p h . n_{\bullet}} / \rho\right) f_{\sigma_{p h} n_{0}}$ has been ignored. In eq (4) the energy-absorption weighting fractions $f_{\text {incoh, }} f_{\tau}, f_{\kappa_{n}}$, and $f_{\kappa_{e}}$ follow the $f$ definition in eq (2), each for the individual interaction process indicated.

Although the incoherent scattering $\sigma_{i n c o h} / \rho$ and triplet production $\kappa_{e} / \rho$ processes produce vacancies in the atomic electron subshells, resulting in the emission of either fluorescence or Auger electrons, existing tables ignore fluorescence emission (in effect, set $\omega_{i}=0$ ) for these processes in which the subshell distribution of vacancy creation is not well known. Computational procedures for evaluating $f_{i n c o h}$ and $f_{k}$ (treating $k_{n}$ and $k_{e}$ alike), ignoring fluorescence, are given, e.g., by Hubbell (77Hu01) and by Higgins et al. (89Hi01). 
For the atomic photoeffect term $(\tau / \rho) f_{\tau}$, Hubbell (77Hu01) calculated $f_{\tau}$ using the formulation by $R$. T. Berger (61Be01), modified as suggested by Carlsson (71Ca01) to include additional fluorescence cascade effects. For each atomic electron shell group $i$, where $i$ signifies $K, L, M, \ldots, a$ photoeffect energy-absorption fraction $f_{\tau_{j}}$ was calculated for each incident photon energy $E_{0}$ and element $Z$ as

$$
\begin{aligned}
f_{\tau_{i}}\left(E_{0}, Z\right)=\left(1-\frac{\eta_{j}}{E_{0}}\right) & \cdot\left[1-G_{b r}\left(E_{0}-\eta_{i}\right)\right] \\
& +\frac{\eta_{i}}{E_{0}}\left(1-\frac{\omega_{i} E_{i}}{\eta_{i}}-N_{i, i+1} \frac{\omega_{i+1} E_{i+1}}{\eta_{i}}\right)
\end{aligned}
$$

in which $\eta_{i}$ is the mean absorption-edge energy of the $i-s h e 11, G_{b r}\left(E_{0}-\eta_{j}\right)$ is the bremsstrahlung yield (see, e.g., Berger and Seltzer (83Be01) and ICRU (84Ic01)) for the photoelectron of energy $E_{0}-\eta_{j}, \omega_{i}$ is the $i-$ shell fluorescence yield, $E_{j}$ is the $i$-shell fluorescence $x$-ray mean energy, and $N_{i, i+1}$ is the average number of vacancies created in the $(i+1)$-shell per primary i-shell vacancy.

For $\mu_{e n} / \rho$ in mixtures, where the bremsstrahlung yield $G_{b r}\left(E_{0}-\eta_{j}\right)$ is a function of the matrix rather than the atom suffering the primary collision, further refinements in the computations have been proposed by Attix (84At01). Since the $K$ fluorescence $x$ rays predominate over the $L x$ rays, and $L$ $x$ rays over $M x$ rays, etc, both in photon energy and yield, particularly for low-Z elements, the approximation $f_{\tau}^{\prime}$ for the photoeffect energy-absorption fraction $f_{\tau}$ has sometimes been used, e.g., by $R_{0}$ T. Berger (61Be01), in computing $\mu_{\mathrm{en}} / \mathrm{p}$ : 
For $E_{0}$ above the $K$ edge:

$$
(\tau / \rho) f_{\tau}^{\prime} \approx\left(\tau_{K} / \rho\right)\left(1-\frac{\omega_{K} \bar{E}_{K}}{E_{0}}\right)+\left(\tau_{L} / \rho\right)+\left(\tau_{M} / \rho\right)+\ldots
$$

which reduces to

$$
f_{\tau}^{\prime} \approx 1-\frac{\left(\tau_{K} / \rho\right)}{(\tau / \rho)}\left(\frac{\omega_{K} \vec{E}_{K}}{E_{0}}\right)
$$

For $E_{0}$ between the $K$ and $L$ edges:

$$
(\tau / \rho) f_{\tau}^{\prime} \approx\left(\tau_{L} / \rho\right)\left(1-\frac{\omega_{L} \bar{E}_{L}}{E_{0}}\right)+\left(\tau_{M} / \rho\right)+\ldots
$$

or

$$
f_{\tau}^{\prime} \approx 1-\frac{\left(\tau_{L} / \rho\right)}{(\tau / \rho)}\left(\frac{\bar{\omega}_{L} \bar{E}_{L}}{E_{0}}\right)
$$

and similarly between the $L$ and $M$ edges:

$$
f_{\tau}^{\prime} \approx 1-\frac{\left(\tau_{M} / \rho\right)}{(\tau / \rho)}\left(\frac{\bar{\omega}_{M} \bar{E}_{M}}{E_{0}}\right) .
$$

with further ad hoc approximations within the $L$ and $M$ multiple-edge regions. 


\section{K-SHELL FLUORESCENCE YIELD $\omega_{K}$}

The bulk of the fluorescence yield measurements reported in the literature have been for the $K$ shell, and this trend has continued through the 1978-1988 period, as indicated in the annotated bibliography in Section VIII in this report. A semi-empirical fitting formula for $\omega_{K}$, introduced by Burhop (55Bu01), has become established in the literature, of the form

$$
\begin{aligned}
\left(\frac{\omega_{K}}{1-\omega_{K}}\right)^{1 / 4} & =c_{0}+c_{1} Z+c_{2} Z^{2}+c_{3} Z^{3} \\
& =\sum_{i=0}^{3} c_{i} z^{i}
\end{aligned}
$$

which can be rewritten

$$
\omega_{K}=\left[\sum_{i=0}^{3} c_{i} z^{i}\right]^{4} /\left\{1+\left[\sum_{i=0}^{3} c_{i} z^{i}\right]^{4}\right\}
$$

This fitting formula is also applicable to average L-shell fluorescence yields $\bar{\omega}_{L}$, as will be seen in Section IV following.

Bambynek et al. (72Ba01), in their 1972 review article (the most comprehensive and widely quoted fluorescence yield reference to date), have fitted their collection of "selected 'most reliable' experimental values," listed in their Table III.IV with parameters for eq (12), above, of values:

$$
\begin{aligned}
& c_{0}=0.015 \pm 0.010 \\
& c_{1}=0.0327 \pm 0.0005 \\
& c_{2}=0 \\
& c_{3}=-(0.64 \pm 0.07) \times 10^{-6} .
\end{aligned}
$$


In Table 1 of this report, $w_{K}$ values for $1 \leqslant Z \leqslant 110$, matching the range of the Krause (79Kr01) table, generated from the above eqs (12) and (13), are given in the first $\omega_{K}$ column, and are compared with measured values (averaged when more than one measurement per element is given) in the next column. In a subsequent review, Krause (79Kr01) incorporated additional new data in a revised evaluation, and presented a table of w "adopted values" for all elements $5 \leqslant Z \leqslant 110$, but did not provide a corresponding parametric fit or fits. These 1979 Krause adopted values are included in Table 1 of this report along with percent differences of these adopted values from the 1972 Bambynek et al. (72Ba01) fit.

In 1984 Bambynek (84Ba01) presented a further reevaluation of $\omega_{K}$, incorporating about 100 new measurements subsequent to the 1972 Bambynek et al. (72Ba01) evaluation. Using a stepwise regression analysis with 119 selected $\omega_{K}$ measurements, Bambynek fitted his new evaluation to the form in eq (12) above, with parameters $C_{j}$ now:

$$
\begin{aligned}
& c_{0}=0.0370 \pm 0.0052 \\
& c_{1}=0.03112 \pm 0.00044 \\
& c_{2}=(5.44 \pm 0.11) \times 10^{-5} \\
& c_{3}=-(1.250 \pm 0.070) \times 10^{-6} .
\end{aligned}
$$

This revised fit was used to generate the $\omega_{K}$ values in the next to the last column in Table 1 for all elements $1 \leqslant Z \leqslant 110$.

For $35 \leqslant Z \leqslant 107$ the 1984 values differ from the 1972 values by less than $1 \%$. For $1 \leqslant Z<34$ the new values exceed the old by more than $1 \%$, and for $1 \leqslant Z \leqslant 11$ by more than 10\%. However, in the range $1 \leqslant Z<11 w_{k}$ is sma11, 
ranging from $2.160 \times 10^{-5}$ for $Z=1$ to 0.02133 for $Z=11$. Since $w_{K}$ enters the computations of photon energy-absorption coefficients $\mu_{\text {en }} / \rho$ approximately as $\left(1-\omega_{K} \frac{\bar{E}_{K}}{E_{0}}\right)$, see eq $(6)$, where $E_{K} / E_{0}<1$, these differences, even the $317 \%$ at $Z=1$, result in less than $1 \%$ differences in $\mu_{\mathrm{en}} / \rho$ for all elements $1 \leqslant Z \leqslant 100$.

The fitting formula eq (12), rewritten from eq (11), with the 1984 Bambynek (84Ba01) parameters in eq (14) is the $\omega_{K}$ evaluation recommended in this report for current $\mu_{\mathrm{en}} / \mathrm{\rho}$ computations, and the numerical values are repeated for convenience in the summary Table 4 for $1 \leqslant Z \leqslant 100$. 
IV. L-SHELL AVERAGE FLUORESCENCE YIELD $\bar{w}_{L}$

The status of fluorescence yield data for the $L$ subshells $L_{1}, L_{2}$ and $L_{3}$, and particularly for the average yield $\bar{\omega}_{L}$, is well summarized in the recent review by Cohen (87C001). Besides tables and standard-form fits (eq (12)) of the uq values given by Bambynek et al. (72Ba01) and by Mitchell and Barfoot (81Mi01), Cohen presents new theoretical values of $\bar{\omega}_{L}$ calculated using the ECPSSR (Energy loss, Coulomb deflection, Perturbed Stationary State, Relativistic effects) theory of Brandt and Lapicki (79BrO1) and the resulting L-shell ionization cross sections computed by Cohen and Harrigan (85C002). Cohen's (87Co01) fitting parameters for $\bar{\omega}_{L}$ in eq (12) are:

Bambynek et al. (72Ba01), $\bar{\omega}_{L}, 23 \leqslant Z \leqslant 96$ :

$$
\begin{aligned}
& C_{0}=0.238209 \\
& c_{1}=-0.00216099 \\
& c_{2}=1.85156 \times 10^{-4} \\
& C_{3}=-7.47647 \times 10^{-7}
\end{aligned}
$$

Mitche11 and Barfoot (81Mi01), $\bar{\omega}_{L}, 23 \leqslant Z \leqslant 92$ :

$$
\begin{aligned}
& c_{0}=0.326968 \\
& c_{1}=-0.00242879 \\
& c_{2}=1.71660 \times 10^{-4} \\
& c_{3}=-6.96583 \times 10^{-7}
\end{aligned}
$$


Cohen (87Co01), $\bar{\omega}_{L}$, ECPSSR, $30 \leqslant Z \leqslant 96$ :

$$
\begin{aligned}
& C_{0}=0.177650 \\
& C_{1}=0.00298937 \\
& C_{2}=8.91297 \times 10^{-5} \\
& C_{3}=-2.67184 \times 10^{-7}
\end{aligned}
$$

Numerical values generated from these fits are compared with the tables presented by Cohen (87C001), in Table 2 of this report.

The Cohen ECPSSR fit, using the above eq (17) parameters, was extended to lower $Z$ 's, down to $Z=3$, the first element with an L-shell electron. The $\bar{w}_{L}$ values computed from the fit for the lowest $Z$ 's appeared too high, exceeding the $u_{K}$ values. However, the Mitchell and Barfoot (81Mi01) table actually extends down to $Z=12$, based on results in a thesis by Hoffmann (78HoOl).

A log-log plot of the Mitchell-Barfoot-Hoffmann values was found to be linear over the range $12 \leqslant Z \leqslant 50$ except for two anomalously low points for $Z=17$ and 18, perhaps due to round-off in the two-digit table. Using the slope of this $\log -10 \mathrm{~g}$ linear plot, and normalizing from 0.024 to the 3-digit 0.0242 ECPSSR Cohen-fit value at $Z=37$ a fit is here presented:

Present work, $\bar{\omega}_{L}, 3 \leqslant Z \leqslant 36$ :

$$
\bar{\omega}_{L}=1.9390 \times 10^{-8} \times z^{3.8874}
$$

In the summary Table $4, \bar{w}_{L}$ is generated using eq (18) for $3 \leqslant Z \leqslant 36$, and eq (12) with the Cohen (87C001) ECPSSR fit parameters in the above eq (17) for $37 \leqslant Z \leqslant 100$, as recommended $\bar{w}_{L}$ values for current $\mu_{\mathrm{en}} / p$ computations. 


\section{M-SHELL AVERAGE FLUORESCENCE YIELD $\bar{\omega}_{M}$}

An extended-range table of $M$-shell average fluorescence yield values $\bar{\omega}_{M}$, suitable for systematic computations of mass energy-absorption coefficients $\mu \mathrm{en}^{\prime} \rho$, was not found in the literature, so this report has undertaken to provide a provisional $\bar{\omega}_{M}$ fit and table.

Burhop (55Bu01) fitted the $\bar{\omega}_{M}$ Lay (34La01) and Jaffe (54Ja01) data available in 1955 by a formula

$$
\bar{\omega}_{M}=1.7 \times 10^{-9}(Z-13)^{4} .
$$

Subsequent measurements by Jopson et al. (65J001), corrected by Bambynek et al. (72Ba01) for a $20 \%$ correction from double M-she1l vacancies to convert $\omega_{L M}$ into $\bar{\omega}_{M}$ data, and by Konstantinov and Sazonova (68Ko01), by Hribar et al. (82Hr01), and by Shatendra et al. (84Sh01) are shown in Table 3. The average difference of all three measurements 1934-1984 from the Burhop (55Bu01) eq (19) values is a factor 0.758 , with no significant trend as a function of $Z$ over this limited high $-Z$ range $76 \leqslant Z \leqslant 92$.

Hence a provisional fit is proposed:

$$
\begin{aligned}
\bar{\omega}_{M} & =0.758 \times 1.7 \times 10^{-9}(Z-13)^{4} \\
& =1.29 \times 10^{-9}(Z-13)^{4}
\end{aligned}
$$

from which numerical values are given in the last column in Table 3, and for the range $13 \leqslant Z \leqslant 100$ in the summary Table 4. 
Also shown in Table 3 , for comparison, are some theoretical $\bar{\omega}_{M}$ values derived from Chen et al. (80Ch02) and given by Sarkar et al. (81Sa01). The Chen et al. (80Ch02) values listed were obtained from their theoretical $\omega_{L_{4}}$ and $\omega_{L_{5}}$ values using a recipe quoted by McGuire (72Mc01) from Jopson et al. (65J001):

$$
\bar{\omega}_{M} \approx \omega_{L M} \approx 0.4 \omega_{M_{4}}+0.6 \omega_{M_{5}} .
$$

The Sarkar et al. (81Sa01) values listed in Table 3 were also derived from the Chen et al. (80Ch02) theoretical $\omega_{M_{i}}$ subshell values, but by Sarkar et al. using the relation

$$
\bar{\omega}_{M}=\sum_{i=1}^{5} \frac{1}{18} N_{M_{i}} \omega_{M_{i}}
$$

in which $N_{M_{i}}$ are the numbers of electrons in each $M_{i}$ subshe11.

Equation (20), used in generating the $\vec{\omega}_{M}$ values listed in the summary Table 4 for $13<Z \leqslant 100$, could be further refined by including additional $\omega_{M_{i}}$ subshell measurements by Karttunen et al. (71Ka01) and by Baker et al. (74Ba01), perhaps combined using eq (22) above. 
VI. N- AND HIGHER-SHELL AVERAGE FLUORESCENCE YIELDS

No N-shell or higher she11 $\omega$ measurements were found in the literature. For the $N$ shell, the best source of $\bar{\omega}_{N}$ data, if required, is probably the theoretical work of McGuire (74Mc01), which provides $\omega_{N_{1}}, \omega_{N_{2}}$, and $\omega_{N_{3}}$ values for 25 elements over the range $38 \leqslant Z \leqslant 103$, and $\omega_{N_{4}}, \omega_{N_{5}}$, and $\omega_{N_{6}, 7}$ values for 20 elements over the range $50 \leqslant Z \leqslant 103$. For average $\bar{\omega}_{N}$ values, this information would need to be combined using an expression analogous to either eq (21) or (22) above. 


\section{SUMMARY AND RECOMMENDATIONS}

Based on information in the works listed in the appended annotated bibliography 1978-1988, and in key earlier works listed in the additional text references, a recommended set of extended-range $\omega_{K}, \bar{\omega}_{L}$, and $\bar{\omega}_{M}$ values is provided in Table 4. These values may be regenerated using the following fits, as described and documented earlier in this report:

$$
\omega_{K}(i<z<100)=\left[\sum_{i=0}^{3} C_{i} z^{i}\right]^{4} /\left\{1+\left[\sum_{i=0}^{3} C_{i} z^{i}\right]^{4}\right\}
$$

where

$$
\begin{aligned}
C_{0} & =0.0370 \pm 0.052 \\
C_{1} & =0.03112 \pm 0.00044 \\
C_{2} & =(5.44 \pm 0.11) \times 10^{-5} \\
C_{3} & =-(1.250 \pm 0.070) \times 10^{-6} \cdot \\
\bar{\omega}_{L}(3 \leqslant Z<36) & =1.9390 \times 10^{-8} \times z^{3.8874} \\
\bar{\omega}_{L}(37 \leqslant Z<100) & =\left[\sum_{i=0} C_{i} Z^{i}\right]^{4} /\left\{1+\left[\sum_{i=0}^{3} C_{i} z^{i}\right]^{4}\right\} \\
C_{0} & =0.177650 \\
C_{1} & =0.00298937 \\
C_{2} & =8.91297 \times 10^{-5} \\
C_{3} & =-2.67184 \times 10^{-7}
\end{aligned}
$$




$$
\bar{\omega}_{M}=(13 \leqslant Z \leqslant 100)=1.29 \times 10^{-9}(Z-13)^{4}
$$

Finally, it should be understood that this report is a provisional working document, addressing the requirement for extended-range systematic.w data as input to computation of photon energy-absorption coefficients $\mu_{\mathrm{en}} / \rho$ as described in Section II, and that corrections, suggestions, and additions, directed to the author, will be welcomed. 
VIII. ANNOTATED BIBLIOGRAPHY OF X-RAY FLUORESCENCE YIELD MEASUREMENTS, ANALYSIS, FITS, AND TABLES 1978-1988

78A101 Allawadhi, K. L., Arora, S. K., and Sood, B. S., Nat1. Acad. Sci. Lett. (India) 1, 109-111 (1978)

Average $L$ Shell Fluorescence Yields Following $K$ to $L$ Transfer of Vacancies in Some High Z Elements

(L: high Z)

78Do01 Doyle, B. L., Schiebel, U., McDonald, J. R., and Ellsworth, L. D., Phys. Rev. A, 17, 523-528 (1978)

Charge-State Dependence of the Mean K-Shell Fluorescence Yields of $\mathrm{Si}{ }^{\mathrm{q}+}$ Ions

(K: Si ions)

79Ah01 Ahmad, I., Z. Phys. A (Germany) 290, 1-5 (1979)

Precision Measurement of K-Shell Fluorescence Yields in Actinide Elements

(K: $\mathrm{Np}, \mathrm{Pu}, \mathrm{Cm}, \mathrm{Bk}, \mathrm{Cf}, \mathrm{Es}$ )

79Ch01 Chen, M. H., Laiman, E., Crasemann, B., Aoyagi, M., and Mark, H., Phys. Rev. A (USA), 19, 2253-2259 (1979).

Relativistic L-She11. Auger and Coster-Kronig Rates and Fluorescence Yields

(Theor: $L_{1}, L_{3}: H g, U, C m ; L_{2}: Y b, W, H g, R a, T h, U, C m$ )

79Hr01 Hribar, M., Kodre, A., and Pahor, J., Fizika (Yugoslavia) 11, 109-115 (1979)

The Study of the L-shell Fluorescence Yields of Tin and Antimony ( $L: S n, S b$ )

79Kr01 Krause, M. 0., J. Phys. and Chem. Ref. Data (USA), 8, 307-327 (1979) Atomic Radiative and Radiationless Yields for $K$ and $L$ Shells. (Review, Tables: $K: 5 \leqslant Z \leqslant 110 ; L: 12 \leqslant Z \leqslant 110$ )

79La01 Langenberg, A. and Van Eck, J., J. Phys. B (GB) 12, 1331-1350 (1979) An Evaluation of $\mathrm{K}$-Shell Fluorescence Yields; Observation of Outer-Shel1 Effects

(Review, fit: $K: 3 \leqslant Z \leqslant 98$ )

79Sp01 Spiler, F. and Hribar, M., Fizika (Yugoslavia) 11, 117-120 (1979)

The New Determination of the L-Shell Fluorescence Yield of Krypton (L: Kr)

79Tu01 Tunnel1, T. W., Can, C., and Bhalla, C. P., IEEE Trans. Nuc1. Sci. (USA) NS-26, Pt. 2, 1124-1126 (1979)

Theoretical Lifetimes and Fluorescence Yields for Multiply-Ionized Fluorine

(Theor.: K: $F$ ions) 
80Bi01 Bissinger, G. Joyce, J. M., Tanis, J. A., and Varghese, S. L., Phys. Lett. A, 77A, 156-158 (1980)

Statistical Scaling of $\mathrm{C}$ and $\mathrm{O} \mathrm{K}$-Shell Fluorescence Yields

( $\mathrm{K}$ : $\mathrm{C}$ in $\mathrm{CH}_{4}, \mathrm{C}_{2} \mathrm{H}_{2}, \mathrm{C}_{2} \mathrm{H}_{4}, \mathrm{C}_{2} \mathrm{H}_{6}, \mathrm{CO}_{2}, \mathrm{CF}_{4} ; \mathrm{O}$ in $\mathrm{O}_{2}, \mathrm{CO}, \mathrm{CO}_{2}, \mathrm{H}_{2} \mathrm{O}$ )

80Ch01 Chen, M. H., Crasemann, B., and Mark, H., Phys. Rev. A (USA) 21, 436-441 (1980)

Relativistic K-Shell Auger Rates, Level Widths, and Fluorescence Yields

(Theor.: K: 25 elements $18 \leqslant Z \leqslant 96$ )

80 Ch02 Chen, M..H., Crasemann, B., and Mark, H., Phys. Rev, A (USA) 21, 449-453 (1980)

Relativistic M-Shell Radiationless Transitions

(Theor.: M: 8 elements $70 \leqslant Z \leqslant 100$ )

80Gn01 Gnade, B. E., Braga, R. A, and Fink, R. W., Phys. Rev。 C (USA) 21, 2025-2032 (1980)

$\mathrm{L}_{2}, 3$-Subshel1 X-Ray Fluorescence and Coster-Kronig Yields at $\cdot Z=64$ and 67

$\left(L_{2}, L_{3}: G d, H o\right)$

80Kr01 Krause, M. 0., Phys. Rev. A (USA) 22, 1958-1961 (1980)

Average L-Shell Fluorescence, Auger, and Electron Yields

(Review: L: $40 \leqslant Z \leqslant 100$ )

80Ma01 Marques, M. I., Martins, M. C., and Ferreira, J. G., Port. Phys (Portuga 1) 11, 9-12 (1980)

The $L_{1}$ Subshell Fluorescence Yield of $\mathrm{Tl}$

$\left(L_{1}: \dagger 1\right)$

80 Ni01 Nigam, A. N. and Napalia, R., Proc. Natt. Acad. Sci. India, Section A, $50,137-144$ (1980)

Screening Effects in Emission of Satellites in L- and M- X-Ray

Spectra

(Screening effects: $L, M$ )

80Ta01 Takasaki, M. and Shima, K., Physica.B and C (Netherlands) $101 \mathrm{C}$, 420-422 (1980)

Ne K-Shell Fluorescence Yield in Collisions Between Ne-Atoms and $\mathrm{Ne}-\mathrm{I}$ Ions at $0.6-2.3 \mathrm{MeV}$

( $\mathrm{K}:$ Ne atoms, ions)

80Ta02 Takiue, M. and Ishikawa, H., Nucl. Instrum. \& Methods (Netherlands) 17 391-394 (1980)

$\mathrm{K}-$ Fluorescence Yields of $\mathrm{Ag}$ and In

(K: $\mathrm{Ag}, \mathrm{In})$

80Ta03 Tanis, J. A., Jacobs, W. W., and Shafroth S. Mo, Phys. Rev。 A (USA) 22, 483-495 (1980)

Systematics of Target and Projecti]e K-X-Ray Production and Radiativ Electron Capture for $20-80-\mathrm{MeV} \mathrm{C1}{ }^{q^{+}}$Ions Incident on $25-200-\mu \mathrm{g} / \mathrm{cm}^{2} \mathrm{C}$ Targets

( $\mathrm{K}: \mathrm{Cl}$ ions) 
81Ar01 Arora, S. K., Allawadhi, K. L., and Sood, B. S., J. Phys. Soc. Jpn. (Japan) 50, 251-254 (1981) Measurement of $\mathrm{L}_{3}$-Shell Fluorescence Yields in $\mathrm{Pb}$, Th and $\mathrm{U}$ $\left(L_{3}: \mathrm{Pb}, \mathrm{Th}, \mathrm{U}\right)^{3}$

81Ar02 Arora, S. K., Allawadhi, K. L., and Sood, B. S., Physica B\&C (Netherlands) $111 \mathrm{C}, 71-75$ (1981)

Measurement of K-Shell Fluorescence Yields in Elements $28 \leqslant Z \leqslant 53$ ( $\mathrm{K}: \mathrm{Ni}, \mathrm{Cu}, \mathrm{As}, \mathrm{Zn}, \mathrm{Se}, \mathrm{Br}, \mathrm{Zr}, \mathrm{Nb}, \mathrm{Mo}, \mathrm{Ag}, \mathrm{In}, \mathrm{Sn}, \mathrm{I}$ )

81Ch01 Chen, M. H., Crasemann, B., and Mark, H., Phys. Rev. A (USA) 24, 177-182 (1981) Widths and Fluorescence Yields of Atomic L-Shell Vacancy States (Theor.: $L_{1}: 18 \leqslant Z \leqslant 100 ; L_{2}: 25 \leqslant Z \leqslant 94 ; L_{3}: 18 \leqslant Z \leqslant 92$ )

81Ko01 Kodre, A., Hribar, M., Ajlec, B., and Pahor, J., Z. Phys. A (Germany) $303,23-26$ (1981)

L-Shel1 Fluorescence Yields of Lead $\left(L_{1}, L_{2}, L_{3}: P b\right)$

81Ku01 Kuhn, U., Genz, H., Low, W., Richter, A, and Merl ler, H.-W., Z. Phys. A (Germany) 300, 103-104 (1981)

Measurement of the K-Shell Fluorescence Yield of $13 \mathrm{Al},{ }^{20} \mathrm{Ca},{ }^{23} \mathrm{~V}$, and 25Mn for Vacancies Produced by the Relativistic Electron Impact (K: $\mathrm{AT}, \mathrm{Ca}, \mathrm{V}, \mathrm{Mn})$

81Ku02 Kurup, M. B., Prasad, K. G., and Sharma, R. P., Nucl. Instrum. \& Methods Phys. Res. (Netherlands) 188, 223-231 (1981)

$X$-Ray Yields by Low Energy Heavy Ion Excitation in Alkali Halide Solid Targets

( $\mathrm{K}: \mathrm{Cl}$, ion energy dependence)

81Ma01 Markevich, D., and Budick, B., J. Phys B (GB) 14, 1553-1563 (1981) Fluorescence Yields for the Rhodium $L$ Shell $\left(L, L_{1}, L_{2}, L_{3}: R h\right)$

81Mi01 Mitchel1, I. Y., and Barfoot, K. M., Nuc1. Sci. Applic. (Harwood, U.K.) $1,99-162$ (1981)

Particle Induced X-Ray Emission Analysis Application to Analytical Problems

(Review, tabulations: $K: 5 \leqslant Z \leqslant 92 ; L: 12 \leqslant Z \leqslant 92 ; M: 82 \leqslant Z \leqslant 92$ )

81Pe01 Petrini, D., J. Phys. B (GB) 14, 3839-3847 (1981)

Theoretical Auger Rates and Fluorescence Yields for some Excited Single K-Vacancy Terms for Boron II

(Theor.: $K_{\text {: }} B$ ions)

81Ro01 Rozet, J. P. and Chetioui, A., J. Phys. B (GB) 14, 73-89 (1981) Non-immediate L-Shell Equilibrium of Fast Heavy Projectiles in Solid Targets: Influence on $K X$-Ray Yield Variation with Target Thickness $(\mathrm{K}: \mathrm{Kr}$ ions $)$ 
81Sa01 Sarkar, M., Mommsen, $H_{0}$, Sarter, W., and Schorkes, P., J. Phys. B (GB) $14,3163-3172$ (1981)

M-She11 X-Ray Production Cross Sections in the Proton Energy Range $250-400 \mathrm{keV}$

(M: Gd, Dy, Ho, Yb, Hf, Ta, W, Pt, Au)

82Hr01 Hribar, M., Kodre, A., and Pahor, J., Physica B\&C (Netherlands) $115 \mathrm{C}$ $132-136$ (1982)

A Study of the M-Shell Fluorescence Yields of Lead

$(\mathrm{M}: \mathrm{Pb})$

82Kr0l Kricke, C. and Brenn, R., Nucl. Instrum. \& Methods Phys. Res. (Netherlands) 202, 107-111 (1982)

Fluorescence Yield of the $2^{4} P_{5 / 2}^{0}$ State of Lithium-like Neon

( $K$ : Ne ions)

82Ta01 Tan, M., Braga, R. A., Fink, R. W., and Venugopala Rao, P., Phys. Scr. (Sweden) 25, 536-542 (1982)

$X$-Ray Fluorescence Yields and Coster-Kronig Transition Probabilities of the $L_{1}, L_{2}$, and $L_{3}$ Subshells of $\mathrm{Pb}$

$\left(L_{1}, L_{2}\right.$, and $\left.L_{3}: P b\right)$

82Tu01 Tunnel1, T. W., Can, C., and Bhalla, C. P., J. Quant. Spectrosc. and Radiat. Transfer (GB) 27, 405-416 (1982)

Theoretical Transition Energies, Lifetimes and Fluorescence Yields 0 : Multiply Ionized Silicon

(Theor.: $K_{2} L_{1}, L_{2}, L_{3}, M_{1}: S i$ ions)

83Ar01 Arndt, E. and Hartmann, E., Phys. Lett. A (Netherlands) 95A, 146-147 (1983)

Deexcitation Rates and Fluorescence Yields of Highly Stripped Atoms ( $\mathrm{K}: \mathrm{Pb}$ ions)

83Ar02 Artamonova, K. P., Valiev, F. F., Grigor'ev, E. P., Zolotavin, A. V., Sergeev, V. O., and Tulina, T. A., Ukr. Fiz. Zh. (USSR) 28, $1447-1450$, (1983)

Fluorescence and Auger Electron Yields for L-Subshells in $151 \mathrm{Gd}$ Deca! $\left(L_{1}, L_{2}, L_{3}: G d\right)$

83Bh01 Bhalla, C. P., IEEE Trans. Nucl. Sci. (USA) NS-30, 1093-1096 (1983)

Lifetimes and Fluorescence Yields of States Produced in Heavy Ion-Atom Collision

(Theor.: heavy ions: $L: 2 \leqslant Z \leqslant 50$ )

83Bh02 Bhalla, C. P., IEEE Trans. Nucl. Sci. (USA) NS-30, 1097-1099 (1983)

Theoretical $X$-Ray Transition Energies and Fluorescence Yields for Multiply-Ionized Oxygen

(Theor.: K: 0 ions)

83Ca01 Can, Co and Bhalla, C. P., IEEE Trans. Nucl. Sci. (USA) NS-30, 1090-1092 (1983)

Theoretical Lifetimes, $X$-Ray Transition Energies and Fluorescence Yields for Double $K$ Vacancy Configurations of Multiply-Ionized Fluorine

(Theor.: K: $F$ ions) 
83Ka01 Karazija, R., Litov. Fiz. Sb. (USSR) 23, 6-16 (1983). Trans in: Sov. Phys.-Collect. (USA) 23, 1-9 (1983)

Approximate Invariance of Auger and Radiative Level Widths and the Fluorescence Yield

(Theor.: effect of inner unfilled shells)

83Ni01 Nicolaides, C. A., Komninos, Y., and Beck, D. R., Phys. Rev. A (USA) $27,3044-3052$ (1983)

$\mathrm{K}$-Shell Binding Energy of Be and Its Fluorescence Yield (K: $\mathrm{Be})$

83Si01 Singh, K., Singh, G., Sharma, R. K., and Sahota, H. S., Phys. Rev. C (USA) 28, 2115-2117 (1983)

$\mathrm{K}$-Shell Fluorescence Yield of Cs

(K: Cs)

83Si02 Singh, N., Mittal, R., Allawadhi, K. L., and Sood, B. S., Physica B\&C (Netherlands) $123 \mathrm{C}, 115 \mathrm{~m} 120$ (1983)

Measurement of the Average L-Shell Fluorescence Yields in Elements. $40 \leqslant Z \leqslant 53$

(L: $\mathrm{Zr}, \mathrm{Nb}, \mathrm{Mo}, \mathrm{Ag}, \mathrm{Cd}, \mathrm{In}, \mathrm{Sn}, \mathrm{I})$

83Su01 Suto, M. and Lee, L. C., 15th Annual Synchrotron Radiation Users Group Conference, Stoughton, WI (USA) 18-19 Oct. (1983) p. 50-51

Fluorescence Yields from Photodissociation of $\mathrm{NH}_{3}$ and $\mathrm{H}_{2} \mathrm{O}_{2}$ (on request)

84Av01 Avaldi, L., Mitchel1, I. V., and Eschbach, H. L., Nucl. Instrum.\&

Methods in Phys. Res. Section B-Beam Interactions with Materials and Atoms, 231 (B3), 21-26 (1984)

Precise X-Ray-Production Cross Section Measurement of Medium-Z

Elements by Protons

$(\mathrm{K}: \mathrm{Cu}, \mathrm{Br})$

84Ba01 Bambynek, W., Proc. X-Ray and Inner-Shell Processes in Atoms, Molecules and Solids, Leipzig Aug. 20-24, 1984

A New Evaluation of K-Shell Fluorescence Yields

(F.it: $K: 5 \leqslant Z \leqslant 100$ )

84Be01 Benka, 0., Nucl. Instrum. \& Methods in Phys. Res. Sect. B

(Netherlands), 232(B4), 279-282 (1984)

The Influence of Multiple Ionization upon Fluorescence Yield

(Theor.: K: $9 \leqslant Z \leqslant 25$ )

84Ca01 Casnati, E., Tartari, A., Baraldi, C., and Napoli, G., J. Phys. B (GB) $17,2413-2419$ (1984)

Experimental K-Shell Fluorescence Yield of Monocrystalline Germanium $(\mathrm{K}: \mathrm{Ge})$

84Sh01 Shatendra, K., Allawadhi, K. L., and Sood, B. S., Physica B\&C

(Netherlands) 124 C, 279 -281 (1984)

Measurement of Average M-Shell Fluorescence Yields in Some High $Z$

Elements

$(M: A u, P b, T h, U)$ 
84Sh02 Shatendra, K. Allawadhi, K. L., and Sood, B. S., Indian J. Phys. Part
A 58A, 366-367 (1984) Measurement of Average Uranium (M: $A u, U)$

84Si01 Singh, K. and Sahota, H. S., J. Phys. G (GB) 10, 241-245 (1984) A New Method of Measuring the K-Shell Fluorescence Yield of As

84Si02 Singh, K., Singh, G., Sharma, R。 K., and Sahota, H. S., Indian J. Phys. Part A 58A, 491-492 (1984)

The K-Shell Fluorescence Yield of CS (K: Cs)

85C001 Combet Farnoux, F., Electronic and Atomic Collisions. 14th International Conference on the Physics of Electronic and Atomic Collisions. Abstracts of Contributed Papers 546 (1985), Coggiola, M J. Huestis, D. L.; Saxon, R. P. (Eds.) $K$ Fluorescence Yields, Auger and X-Ray Decay Rates for Multiply
Ionized Atoms (K: ions)

85Cr01 Crasemann, B., High-Energy Ion-Atom Collisions. Berenyi, D., Hock, G. (Eds.) Proceedings of the 2nd Workshop on High-Energy Ion-Atom Collision Processes, 27-28 Aug 1984, Debrecen, Hungary, PubT: Akademiai Kiado, Budapest, Hungary, 199-221 (1985) Fluorescence Yields and $X-R$ ay Production from Atomic Inner Shells (Review, tabulations: $K: 18 \leqslant Z \leqslant 96 ; L_{1}: 18 \leqslant Z \leqslant 100$;

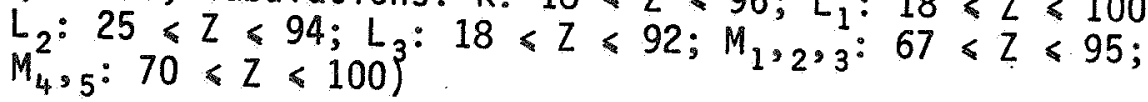

85HaOl Hallak, A. B., Saleh, N. S., and Shabaro, K. M., Appl. Phys. Commun. (USA) $5,241-251$ (1985-86) Measurement of $K-$ and $L \quad X-R a y$ Fluorescence Yield
(on request)

85Ha02 Hanke, W., Wernisch, J., and Pöhn, C., X-Ray Spectrom. 14, 43-47
(1985)

Fluorescence Yields, $\omega_{K}(12 \leqslant Z \leqslant 42)$ and $\omega_{L}(38<Z \leqslant 79)$, from a Comparison of Literature and Experiments (SEM).

(Fits: $K: 12<Z<42$ ); $L_{3}: 30<Z<79$ )

85Ji01 Jitschin, W., Materlik, G., Werner, U., and Funke, P., J. Phys. B (GB) 18, 1139-1153 (1985) Coster-Kronig and Fluorescence Yields of Au L Subshells Derived from
Photoionisation Measurements

$\left(L_{1}, L_{2}, L_{3}: A u\right)$

85Ma01 Marques, M. I., Martins, $M_{0} C_{0}$, and Ferreira, J. G., Phys. Scr. (Sweden) 32, 107-110 (1985)

$L_{1}$ Subshell Yields of $\mathrm{Pt}$ and $\mathrm{Hg}$

$\left(\mathrm{L}_{1}: \mathrm{Pt}, \mathrm{Hg}\right)$ 
85Se01 Sergienko, V. A., Vorontsovskii, A. V., and Naim, M. A., Bul1. Acad. Sci. USSR, Phys. Ser. (USA) 49, 112-116 (1985)

Investigation of the Spectrum of $L X$ and KX-Quanta During the Decay of ${ }^{203} \mathrm{Hg}$ and Determination of the Yjelds of L- and K-Fluorescence for $T I$ Atoms (K, L: T1)

85Si01 Singh, K., Grewal, B. S., and Sahota, H. S., J. Phys. G (GB) 11, $399-405(1985)$

Determination of the $P_{K}$ Values to the 172, 103, and $97 \mathrm{keV}$ Levels and the Fluorescence Yields $\omega_{K}$ of Eu after Electron Capture by ${ }^{153} \mathrm{Gd}$ (K: Eu)

85Si02 Singh, I., Mitta1, R., Allawadhi, K. L., and Sood, B. S., Physica B\&C (Netherlands) 132 C, 119-121 (1985)

Measurement of Average L-Shel1 Fluorescence Yields in Elements

$73 \leqslant Z \leqslant 92$ )

( $L: \mathrm{Ta}, \mathrm{W}, \mathrm{Au}, \mathrm{Hg}, \mathrm{Tl}, \mathrm{Pb}, \mathrm{Bi}, \mathrm{Th}, \mathrm{U})$

86Ar01 Arvanitis, D., Dobler, U., Wenze1, L., Baberschke, K., and Stohr, J., J. Phys. Colloq. (France) 47, 173-178 (1986)

A New Technique for Submonolayer NEXAFS, Fluorescence Vield at the Carbon K-Edge

( $K$ : $C$ at $K$-edge)

86Ba01 Bahn, C., Chaturvedi, S. N., and Nath, N., X-Ray Spectrom. 15, 217-219 (1986)

Fluorescence Cross Sections for $L$ Shell $X$-Ray Lines

( $L: \mathrm{Ho}, \mathrm{Ta}, \mathrm{Au}, \mathrm{Tl}, \mathrm{Pb}, \mathrm{Bi}, \mathrm{Th}, \mathrm{U}$ )

86Ko01 Kodre, A., Hribar, M., and Glavic, D., Z. Phys. D (Germany) 173-176 (1986) The Auger-Raman Effect and the K-Shell Fluorescence Yield of Krypton
$(\mathrm{K}: \mathrm{Kr})$

86Ra01 Rao, N. V., Rao, B. S., Suryanarayana, C., Reddy, S. B., Satyaranarayana, G., and Sastry, D. L., Port. Phys. (Portugal) 17, 35-48 (1986)

Measurement on K X-Ray Fluorescence Yield Ratios in the Region of $55<Z \leqslant 82$ )

(Ratios: $K: 55 \leqslant Z \leqslant 82$ )

86Ro01 Rosato, E., Nucl. Instrum. \& Methods Phys. Res. (Netherlands) B15, 591-594 (1986)

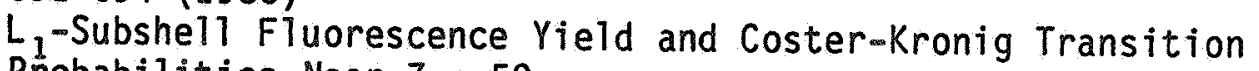
Probabilities Near $Z=50$

$\left(L_{1}: S n\right)$

86Sc01 Schønfeldt, W. A., Mokler, P. H., Hoffmann, D.H.H., and Warczak, A., Z. Phys. D 4, $161 \mathrm{~m} 176$ (1986)

Resonant Electron Transfer and L-Shell Excitation at $3.6 \mathrm{MeV} / \mathrm{u}$ ${ }_{62} \mathrm{Sm}^{\mathrm{q}} \rightarrow \mathrm{Xe}$ Coll isions, $\mathrm{q}=34=52$

(Theor.: $L_{3}:$ Sm ions) 
87A101 Al-Nasr, I. A., Jabr, I. J., AT-Saleh, K. A., and Saleh, N. S., Appt。 Phys. A (Germany) A43, 71-73 (1987)

Measurement of $K_{\alpha}$ Cross Sections and Fluorescence Yields for Elemen in the Range $42 \leqslant Z \leqslant 57$ Using Radioisotope $X$-Ray Fluorescence (K: Mo, Ag, Cd, In, Sn, Sb, Ba, La)

87 Au01 Auerhammer, J., Genz, Ho, and Richter, A., J. Phys. Colloq. (France) $48,621-624$ (1987)

Measurements of L-Subshell Fluorescence Yields for Light Elements $\left(\mathrm{L}_{1}, \mathrm{~L}_{2}, \mathrm{~L}_{3}: \mathrm{Ni}, \mathrm{Cu}, \mathrm{Ge}, \mathrm{Kr}, \mathrm{Sr}, \mathrm{Mo}, \mathrm{Ag}\right)$

87Bh01 Bhalla, R. P., McDaniel, F. D., and Lapicki, G., Nucl. Instrum \& Methods Phys. Res. (Netherlands) B24-B25, 180-183 (1987)

Carbon K-Shell $X$-Ray and Auger-Electron Cross Sections and Fluorescence Yields in Benzene Bombarded by 0.6 to $2.0 \mathrm{MeV}$ Protons
$(\mathrm{K}: \mathrm{C})$

87Br01 Brunner, G., J. Phys. B, At. Mol Phys. (UK) 20, 4983-4991 (1987)

K-Shell Fluorescence Yields of Silicon and Germanium by Detector ( $\mathrm{K}: \mathrm{Si}, \mathrm{Ge})$

87Ca01 Campbe11, J. L., and McGhee, P. L., J. Phys. Colloq. (France) 48, $L$ Subshel1 Fluorescence and Coster-Kronig Yields for $Z=78,80,81$,
and 82 $\left(L_{1}, L_{2}, L_{3}: P t, A u, H g, T l, P b\right)$

87Ch01 Charlton, D. E., Pomplun, E., and Booz, J., Radiat. Res. (USA) 111, 553-564 (1987)

Some Consequences of the Auger Effect: Fluorescence Yield, Charge Potential, and Energy Imparted

(Review, for dosimetry applications)

87Co01 Cohen, $D_{\circ} D_{\circ}$, Nuc1. Instrum. \& Methods Phys Res. (Netherlands) B22, 55-58 (1987)

Average $L$ Shell Fluorescence Yields

(Review, tables, fits: $L: 23<Z<96$ )

87C002 Combet Farnoux, F., J. Phys. Colloq. (France) 48, 199-202 (1987) Multiplet Effects on K Fluorescence Yields of Multiply-Charged Ions

87Fi01 Fischer, D. A., Zaera, F., and Gland, J. L., J. Phys. Colloq. (France) 48, $1097-1100$ (1987)

Fluorescence Yield Near Edge Structure (FYNES): A Novel Technique for In Situ Surface Chemistry

$(K$ : near-edge structure: $C, S$ ) 87Hr01 Hribar, M०, Kodre, $A_{0}$, and Glavic, D., J. Phys. Colloq. (France) 48,
$625-628$ (1987)

Fluorescence Yield of Double $K$ Vacancies in Krypton (Double $K$ vacancy: $K r$ ) 
87Lo01 Lorenz, M. and Hartmann, E., J. Phys. B, At. Mol. Phys. (UK) 20, 6189-6195 (1987) Effect of L-Shell Spectator Vacancy on X-Ray Fluorescence Yields and

$\left(L_{1}, L_{2}, L_{3}: I n, P b\right)$

87Ph01 Phillips, $W_{0} R_{0}$, Rehm, K. E., Henning, W., Ahmad, I., Schiffer, J. P., Glagola, B., and Wang, T. F., J. Phys. Colloq. (France) 48, 311-313 (1987)

K-Shell Fluorescence Yields in Highly Stripped $57 \mathrm{Fe}$ Atoms

( $\mathrm{K}: \mathrm{Fe}$ ions)

87We01 Werner, U. and Jitschin, W., J. Phys. Colloq. (France) 48, 559-562 (1987)

Radiative, Auger, and Coster-Kronig Yields Obtained by the Synchroton Photoionization Technique

$\left(L_{1}, L_{2}, L_{3}: 72 \leqslant Z \leqslant 82\right.$ : Measurements described but results not presented)

87Xu01 Xu, J. Q. and Rosato, E., J. Phys. Colloq. (France) 48, 661-664 (1987) Relative Intensities of Diagram and Satellite L-X-Rays for Elements $37 \leqslant Z<56$

(Analysis: $L_{1}: 37 \leqslant Z \leqslant 56$ )

88Au01 Auerhammer, J., Genz, H., and Richter, A., Z. Phys. D, At. Mol. Clusters (West Germany) 7, 301-307 (1988)

Measurements of L-Subshell Fluorescence Yields for Light and Medium Heavy Elements $(28 \leqslant Z \leqslant 47)$ $\left(L_{1}, L_{2}, L_{3}: \mathrm{Ni}, \mathrm{Cu}, \mathrm{Ge}, \mathrm{Kr}, \mathrm{Sr}, \mathrm{Mo}, \mathrm{Ag}\right)$

88Ch01 Chen, M. H. and Crasemann, B., At. Data Nucl. Data Tables (USA) 38, 381-424 (1988)

K-Shell Auger and Radiative Transitions in the Boron Isoelectronic Sequence

(Theory: tables: K: C, N, O, F, Ne, Mg, Si, S, Ar, Ca, Ti, Fe, Zn, $\mathrm{Kr}, \mathrm{Mo}, \mathrm{Ag}, \mathrm{Xe}$ )

88Ha01 Hartmann, E., J. Phys. B, At. Mol. Opt. Phys. (UK) 21, 1173-1182 (1988) $X$-Ray Fluorescence Yields for Light Emitter Atoms: Carbon

(Theor.: $\mathrm{K}: \mathrm{C}$ )

88Ha02 Hartmann, E. and Der, R., J. Phys. B, At. Mol. Opt. Phys. (UK) 21, 1751-1760 (1988)

$X$-Ray Fluorescence Yields for Light Emitter Atoms: Fluorine (Theor.: K: F)

88Mc01 McGhee, P. L. and Campbe11, J. L., J. Phys. B, At. Mo1. Opt. Phys. (UK) 21, 2295-2309 (1988)

Measurement of Coster-Kronig and Fluorescence Yields of the $L_{2}$ and $L_{3}$
Subshells of Heavy Atoms $\left(\mathrm{L}_{2}, \mathrm{~L}_{3}: \mathrm{Pt}, \mathrm{Hg}, \mathrm{Tl}, \mathrm{Pb}, \mathrm{U}, \mathrm{Cm}\right)$ 
88Mi01 Miyagawa, Y., Nakamura, S., and Miyagawa, S., Nucl. Instrum. \& Methods Phys. Res. B, Beam Interact. Mater. At. (Netherlands) B30, 115-122 (1988)

Analytical Formulas for Ionization Cross Sections and Coster-Kronig Corrected Fluorescence Yields of the $L_{1}, L_{2}$, and $L_{3}$ Subshells

(Fits: $L_{1}, L_{2}, L_{3}: 40<Z \leqslant 92$ )

88Mo01 Mohan, H., Singh, P. S., Singh, D., Verma, H. R., and Khurana, Co So, Indian J. Phys. A (India) 62A, 680-684 (1988)

Average L-Shell Fluorescence Yield Measurements in $\mathrm{Sn}$ and Te by Proton Bombardment

(L: $\mathrm{Sn}, \mathrm{Te}$ )

88Ra01 Rani, A., Koshal, R. K., Chaturvedi, S. N., and Nath, N., X-Ray Spectrometry, 17, 53-54 (1988)

Photon-Excited K X-Ray Fluorescence Cross-Section Measurements for Some Low-Z Elements

( $\mathrm{K}$ (relative to $\mathrm{Ca}$ ): $\mathrm{Na}, \mathrm{Mg}, \mathrm{Al}, \mathrm{Si}, \mathrm{S}, \mathrm{Cl}, \mathrm{K}$ )

88Sa01 Sahota, H. S., Singh, R., and Sidhu, N.P.S., X-Ray Spectrom, 17, 99-10 (1988)

Average L Shell Fluorescence Yields from $L$ Shell Vacancies in

Radionuclides

( $L: P r, S m, T b, D y, T m, B i, U, N p, P u$ )

88Si01 Sidhu, N.P.S., Grewal, B. S., and Sahota, H. S., X-Ray Spectrom. (UK) $17,29 \ldots 31$ (1988)

K-Shell Fluorescence Yields of Some Elements from Nuclear Decay

Parameters

(K: As, Cs, Pr, Eu, Dy, Lu, Ta, Hg)

88Ta01 Tan, M., Braga, R. A., Fink, R. W., and Venugopala Rao, P., Phys. Scr. (Sweden) 37, 62-65 (1988)

$\mathrm{L}_{2,3}$ Subshell X-Ray Fluorescence Yields and Coster-Kronig Transition Probabilities of $\mathrm{Nd}$ and $\mathrm{Yb}_{\mathrm{b}}$

$\left(L_{2}, L_{3}: N d, Y b\right)$

88We01 Werner, U. and Jitschin, W., Phys. Rev. A, 38, 4009-4018 (1988)

$L-V a c a n c y$ Decay in Heavy Elements $(72<Z \leqslant 82$ ) by the Synchrotron Photoionization Method

$\left(L_{1}, L_{2}, L_{3}: H f, W, I r, P t, A u, P b\right)$

88Xu01 Xu, J. Q. and Rosato, E., Nucl. Instrum. \& Methods Phys. Res. B, Beam Interact. Mater. At. (Netherlands) B33, 297-300 (1988)

Decay Rates of $2 s$ Vacancies for the Elements $37 \leqslant Z \leqslant 56$

(Analysis: $L_{1}: 37<Z<56$ ) 


\section{ADDITIONAL TEXT REFERENCES}

09Sa01 Sadler, C. A., Phil. Mag. (Ser. 6) 18, 107-132 (1909)

Transformations of X-Rays.

17Ba01 Bark1a, C. G., Phil. Trans. Roy. Soc. London A 217, 315-360 (1917)

On $X$-Rays and the Theory of Radiation

23Wi01 Wilson, C.T.R., Proc. Roy. Soc. (London) A 104, 1-24, + 12 plates (1923)

Investigations on X-Rays and B-Rays by the Cloud Method. Part I. $X$-Rays

23Wi02 Wilson, C.T.R., Proc. Roy. Soc. (London) A 104, 192-212, + 9 plates (1923)

Investigations on $X$-Rays and $\beta$-Rays by the Cloud Method. Part II. B-Rays

25Au01 Auger, P., Compt. Rend. 180, 65-68 (1925)

Sur les rayons $\beta$ secondaires produits dans un gaz par des rayons $X$

25Au02 Auger, P., J. de Physique et le Radium (ser.6) 6 , 205-208 (1925)

Sur l'effet photoelectrique compose

34La01 Lay, H., Z. F. Physik 91, 533-550 (1934).

Die Fluoreszenzausbeute des L-Gebiets.

35Co01 Compton, A. H., and Allison, S. K., X-Rays in Theory and Experiment, 2nd ed. (Van Nostrand 1935) p. 477-492.

54Ja01 Jaffe, A. A., Bul1. Res. Coun. Israel 3, 316-320. (1954); see also Phys. Abstr. 58, 360 (1955).

The $M X-R$ ay from Radium $D$ and the $M X$-Ray Fluorescence Yield of Bismuth.

55Bu01 Burhop, E.H.S., J. Physique et le Radium 16, 625-629 (1955)

Le rendement de fluorescence.

-61Be01 Berger, R. T., Rad. Res. 15, 1-29 (1961).

The X- or Gamma-Ray Energy Absorption or Transfer Coefficient:

Tabulations and Discussion.

65Jo01 Jopson, R. C., Mark, H., Swift, C. D., and Williamson, M.A., Phys, Rev。 A 137, 1353-1357 (1965)

M-Shell Fluorescence Yields of Bismuth, Lead, Gold, and Osmium.

66Fi01 Fink, R. W., Jopson, R. C., Mark, H., and Swift, D. C., Rev. Mod. Phys. 38, 513-540 (1966)

Atomic Fluorescence Yields 
68Ko01 Konstantinov, A. A. and Sazonova, T. E., Bu11. Acad. Sci. USSR (Phys. Ser.) 32, 581-584 (1968); transl. from Izv. Akad. Nauk SSSR (Ser. Fiz.) $\overline{32}, 631-635$ (1968)

Determination of the M-Fluorescence Coefficients of Gold, Lead, and Bismuth.

69Hu01 Hubbe11, J. H., Report NSRDS-NBS 29 (1969)

Photon Cross Sections, Attenuation Coefficients, and Energy Absorption Coefficients from $10 \mathrm{keV}$ to $100 \mathrm{GeV}$.

71Ca01 Carlsson, G. A., Health Phys. 20, 653-655 (1971)

A Criticism of Existing TabuTations of Mass Energy Transfer and Mass Energy Absorption Coefficients.

$71 \mathrm{Ka} 01$ Karttunen, E., Freund, H. U., and Fink, R. W., Phys. Rev. A $\underline{4}$, 1695-1705 (1971)

$M-S h e 11$ Fluorescence Yields and the $L_{1}-L_{3}$ Radiative Transition at $Z=93$ and 96 from Am241 and Cf249 Decays.

72Ba01 Bambynek; W., Crasemann, B., Fink, R. W., Freund, H.-U., Mark, H., Swift, C. D., Price, R. E., and Rao, P. V., Rev. Mod. Phys. 44, 716-813 (1972); erratum in 46, 853 (1974).

X-Ray Fluorescence Yields, Auger, and Coster-Kronig Transition Probabilities.

72Mc01 McGuire, E. J., Phys. Rev. A $\underline{5}, 1043-1047$ (1972).

Atomic M-Sheil Coster-Kronig, Auger, and Radiative Rates, and Fluorescence Yields for $\mathrm{Ca}-\mathrm{Th}$.

73Dy01 Dyson, N. A., X-Rays in Atomic and Nuclear Physics (Longman 1973) p. 78-81.

74Ba01 Baker, K. A., Tolea, F., Fink, R. W., and Pinajian, J. J., Z. Physik 270, 1-7 (1974).

Mean M-Subshell Fluorescence Yields at $Z=88,90,92$, and 94.

74Mc01 McGuire, E. J., Phys. Rev. A 9, 1840-1851 (1974).

Atomic N-Shell Coster-Kronig, Auger, and Radiative Rates and Fluorescence Yields for $38 \leqslant Z \leqslant 103$.

77Hu01 Hubbe11, J. H., Rad. Res. 70, 58-81 (1977)

Photon Mass Attenuation and Mass Energy-Absorption Coefficients for $\mathrm{H}, \mathrm{C}, \mathrm{N}, \mathrm{O}, \mathrm{Ar}$, and Seven Mixtures from $0.1 \mathrm{keV}$ to $20 \mathrm{MeV}$.

78Ho01. Hoffmann, D.H.H., Ph.D. Thesis D-17, Technische Hochschule Darmstadt $(1978)$, p. 108.

79Br01 Brandt, W., and Lapicki, G., Phys. Rev. A 20, 465-480 (1979)

L-Shel1 Coulomb Ionization by Heavy Charged Particles.

82Hu0l Hubbe11, J. H., Int. J. App1. Rad. Isot. 33, 1269-1290 (1982).

Photon Mass Attenuation and Energy-Absorption Coefficients from $1 \mathrm{keV}$ to $20 \mathrm{MeV}$. 
82Te01 Tertian, R. and Claisse, F., Principles of Quantitative X-Ray Fluorescence Analysis (Heyden 1982) p. 12-14.

83Be01 Berger, M. J. and Seltzer, S. M., Report NBSIR 82-2550-A (Revised edition issued 1983)

Stopping Powers and Ranges of Electrons and Positrons (2nd. Ed.)

84At01 Attix, F. H., Phys. Med. Biol. 29, 869-871 (1984)

Energy-Absorption Coefficients for $\gamma$-Rays in Compounds or Mixtures.

84Ic01 ICRU Report 37 (1984) (M. J. Berger, Report Committee Chairman)

Stopping Powers for Electrons and Positrons.

85Co01 Cohen, D. D. and Harrigan, M., At. Data Nucl. Data Tables 33, 255-343 (1985)

$\mathrm{K}$ - and L-Shell Ionization Cross Sections for Protons and Helium Ions Calculated in the ECPSSR Theory.

89Hi01 Higgins, P. D., Sibata, C. H., Attix, F. H., Hubbe11, J. H., Seltzer, S. M., and Berger, M. J., in prep. for Med. Phys. Mass Energy Transfer and Absorption Coefficients, including In-Flight Positron Annihilation.

89Ic01 ICRU Report 44 (1989) (D. R. White, Report Committee Chairman) Tissue Substitutes in Radiation Dosimetry and Measurement.

89Tr01 Trehan, P. N. (Panjab University, Chandigarh, India), personal communication as part of Indo/U.S. joint project on measurement and analysis of photoionization and fluorescence yield data. 


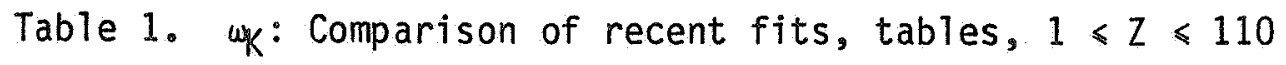

\begin{tabular}{|c|c|c|c|c|c|c|c|}
\hline$Z$ & $\begin{array}{l}\text { Bambynek } \\
\text { et al.9 } \\
1972 \text { fit }\end{array}$ & $\begin{array}{l}\text { Bambynek } \\
\text { et al } \\
1972 \\
\text { most rel. } \\
\text { exper. }\end{array}$ & $\begin{array}{l}\% \text { diffs } \\
\text { exper. } \\
\text { from } \\
1972 \text { fit }\end{array}$ & $\begin{array}{c}\text { Krause } \\
1979 \\
\text { adopted } \\
\text { table }\end{array}$ & $\begin{array}{l}\% \text { diffs } \\
1979 \\
\text { adopted } \\
\text { from } \\
1972 \text { fit }\end{array}$ & $\begin{array}{l}\text { Bambynek } \\
1984 \text { fit }\end{array}$ & $\begin{array}{c}\% \text { diffs } \\
1984 \text { fit } \\
\text { to } \\
1972 \text { fit }\end{array}$ \\
\hline 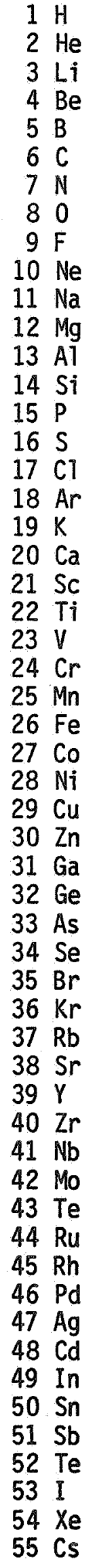 & 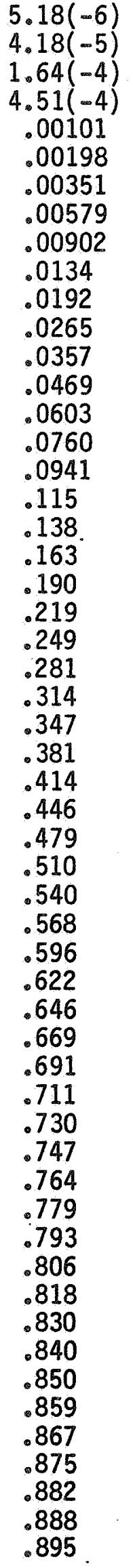 & $\begin{array}{l}.190 \\
.221 \\
.253 \\
.283 \\
.313 \\
.342 \\
.366 \\
.443 \\
.528 \\
.554 \\
.589\end{array}$ & $\begin{array}{r}0 \\
.9 \\
1.6 \\
.7 \\
-.3 \\
-1.4 \\
-3.9 \\
-.7 \\
3.5 \\
2.6 \\
3.6\end{array}$ & 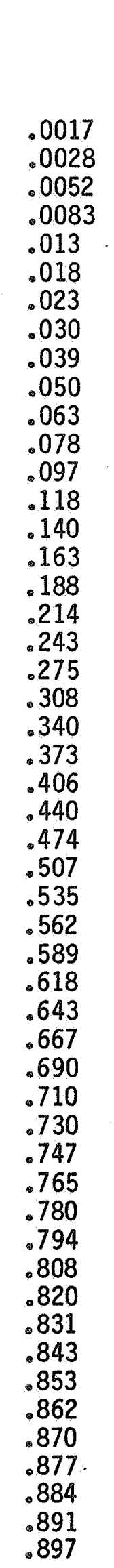 & 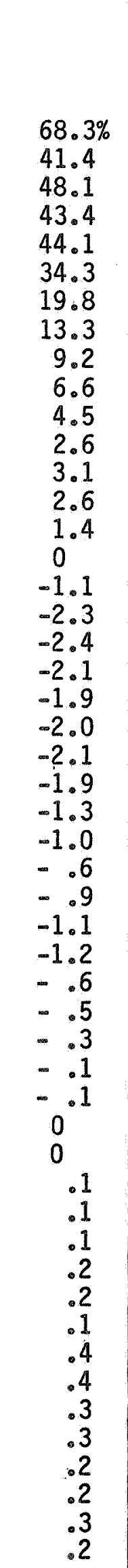 & 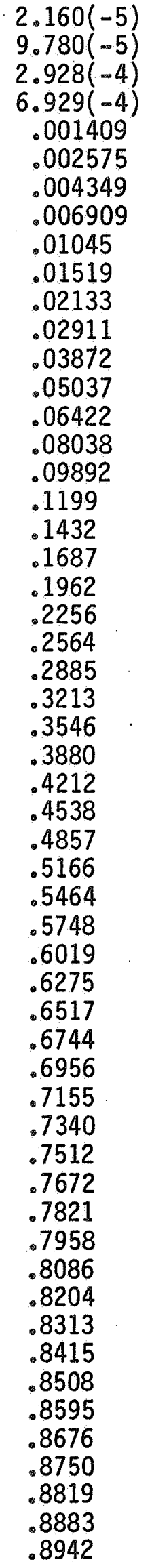 & $\begin{array}{l}317 \% \\
134 \\
78.5 \\
53.6 \\
39.5 \\
30.1 \\
23.9 \\
19.3 \\
15.9 \\
13.4 \\
11.1 \\
9.8 \\
8.5 \\
7.4 \\
6.5 \\
5.8 \\
5.1 \\
4.3 \\
3.8 \\
3.5 \\
3.3 \\
3.0 \\
3.0 \\
2.7 \\
2.3 \\
2.2 \\
1.8 \\
1.7 \\
1.7 \\
1.4 \\
1.3 \\
1.2 \\
1.2 \\
1.0 \\
.9 \\
.9 \\
.8 \\
0 \\
0 \\
.1 \\
.7 \\
.6 \\
.5 \\
.6 \\
.4 \\
.4 \\
.4 \\
.3 \\
.3 \\
.2 \\
.2 \\
.1 \\
.1 \\
.0\end{array}$ \\
\hline
\end{tabular}


Table 1. Continued

\begin{tabular}{|c|c|c|c|c|c|c|c|}
\hline$Z$ & $\begin{array}{l}\text { Bambynek } \\
\text { et al. } \\
1972 \mathrm{fit}\end{array}$ & $\begin{array}{l}\text { Bambynek } \\
\text { et al. } \\
1972 \\
\text { most rel. } \\
\text { exper. }\end{array}$ & $\begin{array}{l}\% \text { diffs } \\
\text { exper. } \\
\text { from } \\
1972 \text { fit }\end{array}$ & $\begin{array}{c}\text { Krause } \\
1979 \\
\text { adopted } \\
\text { table }\end{array}$ & $\begin{array}{c}\% \text { diffs } \\
1979 \\
\text { adopted } \\
\text { from } \\
1972 \text { fit }\end{array}$ & $\begin{array}{l}\text { Bambynek } \\
1984 \text { fit }\end{array}$ & $\begin{array}{l}\% \text { diffs } \\
1984 \text { fit } \\
\text { to } \\
1972 \text { fit }\end{array}$ \\
\hline 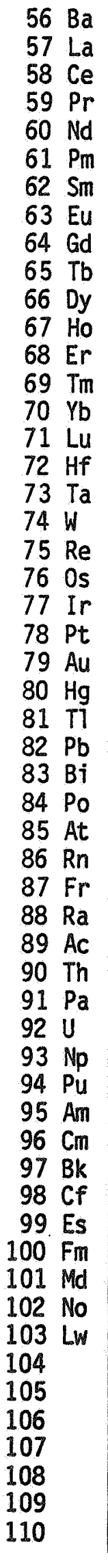 & 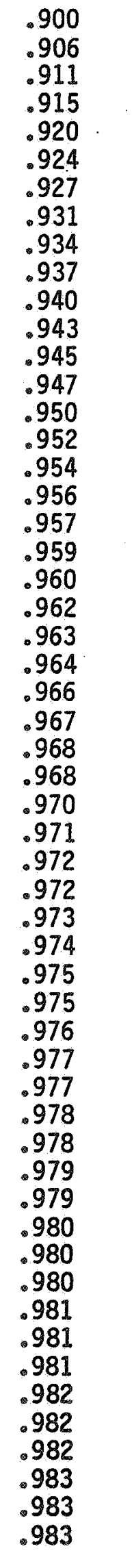 & $\begin{array}{l}.925 \\
.943\end{array}$ & $\begin{array}{r}.4 \\
-.8 \\
.4\end{array}$ & 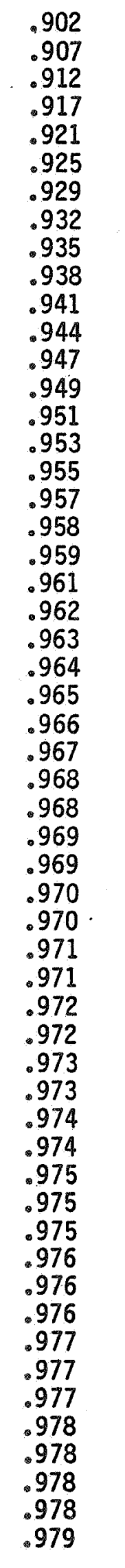 & 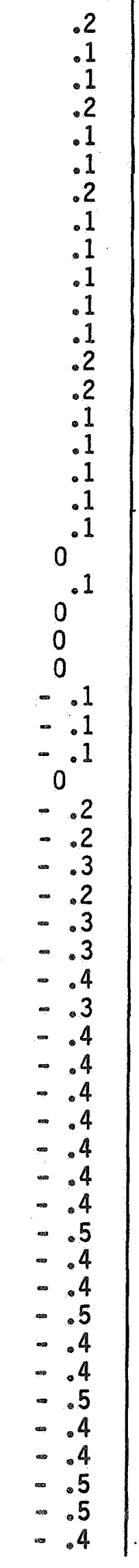 & $\begin{array}{l}.8997 \\
.9047 \\
.9096 \\
.9140 \\
.9181 \\
.9220 \\
.9255 \\
.9289 \\
.9320 \\
.9349 \\
.9376 \\
.9401 \\
.9425 \\
.9447 \\
.9467 \\
.9487 \\
.9505 \\
.9522 \\
.9538 \\
.9553 \\
.9567 \\
.9580 \\
.9592 \\
.9604 \\
.9615 \\
.9625 \\
.9634 \\
.9643 \\
.9652 \\
.9733 \\
.9659 \\
.9733 \\
.9732\end{array}$ & 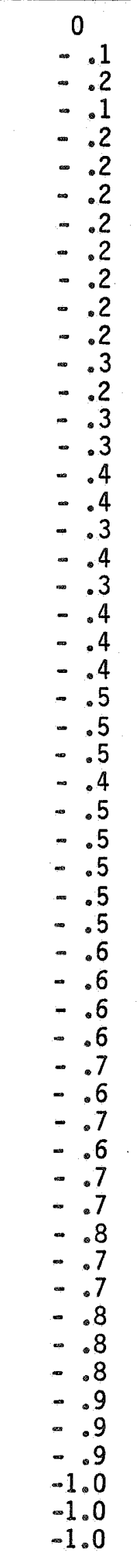 \\
\hline
\end{tabular}


Table 2. Summary and analysis of Cohen ( $87 \mathrm{CO} 01$ ) $\bar{\omega}$ review, fits, and tabulations, including ECPSSR (Energy loss, Coulomb deflection, Perturbed Stationary State, Relativistic effects)

\begin{tabular}{|c|c|c|c|c|c|c|c|c|c|}
\hline$z$ & $\begin{array}{l}\text { Bambynek } \\
\text { et al } \frac{\text { al }}{1972}: \\
\overline{\text { w }} \\
\text { table }\end{array}$ & $\begin{array}{c}\text { Bambynek } \\
\text { et } \frac{\text { al }}{1972}=2 \\
\text { fit }\end{array}$ & $\begin{array}{l}\% \text { diff. } \\
\text { fit } \\
\text { from } \\
\text { table }\end{array}$ & $\begin{array}{c}\text { Mitchell } \\
\text { \& Barfoot } \\
1981 \\
\text { जu } \\
\text { tabTe }\end{array}$ & $\begin{array}{l}\text { Mitchell } \\
\text { \& Barfoot } \\
1981 \\
\text { fit } \\
\text { fit }\end{array}$ & $\begin{array}{l}\% \text { diff. } \\
\text { fit } \\
\text { from } \\
\text { table }\end{array}$ & $\begin{array}{c}\text { Cohen } \\
1987 \\
\text { ECPSSR } \\
\bar{\omega} \\
\text { table }\end{array}$ & $\begin{array}{c}\text { Cohen } \\
1987 \\
\text { ECPSSR } \\
\tilde{\omega}_{1} \\
\text { fit }^{2}\end{array}$ & $\begin{array}{c}\% \text { diff. } \\
\text { fit } \\
\text { tafom }\end{array}$ \\
\hline $\begin{array}{ll}23 & \mathrm{~V} \\
24 & \mathrm{Cr} \\
25 & \mathrm{Mn} \\
26 & \mathrm{Fe} \\
27 & \mathrm{Co} \\
28 & \mathrm{Ni} \\
29 & \mathrm{Cu} \\
30 \mathrm{Zn} \\
31 \mathrm{Ga} \\
32 \mathrm{Ge} \\
33 & \mathrm{As} \\
34 & \mathrm{Se} \\
35 & \mathrm{Br} \\
36 & \mathrm{Kr} \\
37 & \mathrm{Rb} \\
38 & \mathrm{Sr} \\
39 & \mathrm{Y} \\
40 & \mathrm{Zr} \\
41 & \mathrm{Nb} \\
42 & \mathrm{Mo} \\
43 & \mathrm{Te} \\
44 & \mathrm{Ru} \\
45 & \mathrm{Rh} \\
46 & \mathrm{Pd} \\
47 & \mathrm{Ag} \\
48 & \mathrm{Cd} \\
49 & \mathrm{In} \\
50 & \mathrm{Sn} \\
51 & \mathrm{Sb} \\
52 & \mathrm{Te} \\
53 & \mathrm{I} \\
54 & \mathrm{Xe} \\
55 & \mathrm{Cs} \\
56 & \mathrm{Ba} \\
57 & \mathrm{La} \\
58 & \mathrm{Ce} \\
59 & \mathrm{Pr}\end{array}$ & $\begin{array}{r}.107 \\
.089 \\
.093 \\
.101 \\
.123\end{array}$ & $\begin{array}{l}.0804 \\
.0867 \\
.0934 \\
.101\end{array}$ & $\begin{array}{c}. \\
=24.9 \\
=\quad 2.6 \\
+\quad .43 \\
-\quad 5.7\end{array}$ & $\begin{array}{l}.0081 \\
.0093 \\
.011 \\
.012 \\
.014 \\
.015 \\
.017 \\
.019 \\
.022 \\
.024 \\
.027 \\
.030 \\
.033 \\
.036 \\
.040 \\
.043 \\
.047 \\
.052 \\
.056 \\
.061 \\
.066 \\
.071 \\
.077 \\
.082 \\
.089 \\
.096 \\
.102 \\
.110 \\
.117 \\
.125 \\
.133 \\
.141\end{array}$ & $\begin{array}{l}.0201 \\
.0213 \\
.0226 \\
.0240 \\
.0255 \\
.0271 \\
.0289 \\
.0308 \\
.0329 \\
.0351 \\
.0375 \\
.0401 \\
.0428 \\
.0458 \\
.0489 \\
.0522 \\
.0558 \\
.0596 \\
.0637 \\
.0679 \\
.0726 \\
.0774 \\
.0825 \\
.0879 \\
.0936 \\
.0996 \\
.106 \\
.113 \\
.119 \\
.127 \\
.134 \\
.142\end{array}$ & $\begin{array}{c} \\
+148 . \\
129 . \\
105 . \\
100 . \\
82.1 \\
80.7 \\
70.0 \\
62.1 \\
49.5 \\
46.3 \\
38.9 \\
33.7 \\
29.7 \\
27.2 \\
22.3 \\
21.4 \\
18.7 \\
14.6 \\
13.8 \\
11.3 \\
10.0 \\
9.0 \\
7.1 \\
7.2 \\
5.2 \\
3.8 \\
3.9 \\
2.9 \\
1.7 \\
1.6 \\
.75 \\
.71\end{array}$ & $\begin{array}{l}.0092 \\
.0105 \\
.0117 \\
.0131 \\
.0145 \\
.0161 \\
.0177 \\
.0198 \\
.0219 \\
.0241 \\
.0262 \\
.0288 \\
.0313 \\
.0344 \\
.0374 \\
.0406 \\
.0438 \\
.0471 \\
.0503 \\
.0544 \\
.0584 \\
.0629 \\
.0673 \\
.0724 \\
.0774 \\
.0828 \\
.0882 \\
.102 \\
.101 \\
.108 \\
.115 \\
.123\end{array}$ & $\begin{array}{l}.0111 \\
.0121 \\
.0132 \\
.0145 \\
.0158 \\
.0172 \\
.0188 \\
.0204 \\
.0222 \\
.0242 \\
.0263 \\
.0285 \\
.0309 \\
.0335 \\
.0363 \\
.0393 \\
.0425 \\
.0459 \\
.0495 \\
.0534 \\
.0575 \\
.0618 \\
.0665 \\
.0714 \\
.0765 \\
.0820 \\
.0877 \\
.0938 \\
.100 \\
.107 \\
.114 \\
.121\end{array}$ & $\begin{array}{r}+20.7 \% \\
15.2 \\
12.8 \\
10.7 \\
9.0 \\
6.8 \\
6.2 \\
3.0 \\
1.4 \\
.42 \\
.38 \\
-1.0 \\
-6.4 \\
-2.6 \\
-2.9 \\
-3.2 \\
-3.0 \\
-2.5 \\
-1.6 \\
-1.8 \\
-1.5 \\
-1.7 \\
-1.2 \\
-1.4 \\
-1.2 \\
-\quad .97 \\
-\quad .57 \\
-\quad 8.04 \\
-\quad .99 \\
-\quad .93 \\
-\quad .87 \\
-1.63\end{array}$ \\
\hline
\end{tabular}


Table 2. Continued

\begin{tabular}{|c|c|c|c|c|c|c|c|c|c|}
\hline$Z$ & $\begin{array}{l}\text { Bambynek } \\
\text { et al. } \\
1 \frac{19}{972} \\
\text { table }\end{array}$ & $\begin{array}{l}\text { Bambynek } \\
\text { et } \frac{a 1}{1972} \\
\text { fit }\end{array}$ & $\begin{array}{c}\% \text { diff. } \\
\text { fit } \\
\text { from } \\
\text { table }\end{array}$ & $\begin{array}{c}\text { Mitchell } \\
\text { \& Barfoot } \\
1981 \\
\bar{\omega} \\
\text { tabTe }\end{array}$ & $\begin{array}{c}\text { Mitchell } \\
\text { \& Barfoot } \\
1981 \\
\text { wit } \\
\text { fit }\end{array}$ & $\begin{array}{c}\% \text { diff. } \\
\text { fit } \\
\text { from } \\
\text { table }\end{array}$ & $\begin{array}{l}\text { Cohen } \\
1987 \\
\text { ECPSSR } \\
\text { w. } \\
\text { table }\end{array}$ & $\begin{array}{c}\text { Cohen } \\
1987 \\
\text { ECPSSR } \\
\bar{\omega}_{j} \\
\text { fit }\end{array}$ & $\begin{array}{c}\% \text { diffo } \\
\text { fit } \\
\text { from } \\
\text { rable }\end{array}$ \\
\hline 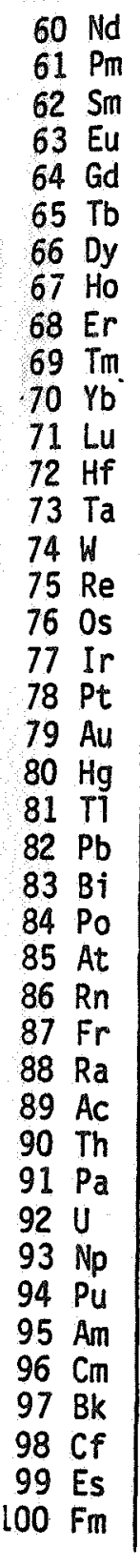 & $\begin{array}{l}.451 \\
.488 \\
.51 \\
.51 \\
.575 \\
.581 \\
.531\end{array}$ & $\begin{array}{l}.472 \\
.498 \\
.511 \\
.524 \\
.537 \\
.549 \\
.572\end{array}$ & $\begin{array}{r}4.66 \\
2.05 \\
.20 \\
2.75 \\
-6.61 \\
-5.51 \\
+7.72\end{array}$ & $\begin{array}{l}.150 \\
.158 \\
.168 \\
.177 \\
.187 \\
.197 \\
.207 \\
.217 \\
.228 \\
.239 \\
.250 \\
.261 \\
.272 \\
.284 \\
.296 \\
.308 \\
.320 \\
.332 \\
.344 \\
.356 \\
.369 \\
.381 \\
.393 \\
.406\end{array}$ & $\begin{array}{l}.150 \\
.159 \\
.168 \\
.177 \\
.187 \\
.196 \\
.206 \\
.217 \\
.227 \\
.238 \\
.249 \\
.261 \\
.272 \\
.284 \\
.296 \\
.308 \\
.320 \\
.332 \\
.344 \\
.357 \\
.369 \\
.382 \\
.394 \\
.406\end{array}$ & $\begin{array}{l}0 \\
0.63 \\
0 \\
0 \\
-.51 \\
-.48 \\
0 \\
=.44 \\
-.42 \\
-.40 \\
0 \\
0 \\
0 \\
0 \\
0 \\
0 \\
0 \\
0 \\
+.28 \\
0 \\
+.26 \\
.25 \\
0\end{array}$ & $\begin{array}{l}.130 \\
.138 \\
.145 \\
.154 \\
.162 \\
.172 \\
.181 \\
.191 \\
.201 \\
.210 \\
.220 \\
.231 \\
.242 \\
.255 \\
.267 \\
.280 \\
.293 \\
.305 \\
.318 \\
.332 \\
.345 \\
.359 \\
.372 \\
.385 \\
.398 \\
.411 \\
.423 \\
.436 \\
.448 \\
.461 \\
.475 \\
.487 \\
.499 \\
.510 \\
.522 \\
.535 \\
.547\end{array}$ & $\begin{array}{l}.129 \\
.137 \\
.145 \\
.153 \\
.163 \\
.172 \\
.182 \\
.192 \\
.202 \\
.212 \\
.223 \\
.234 \\
.245 \\
.257 \\
.269 \\
.281 \\
.293 \\
.305 \\
.318 \\
.331 \\
.343 \\
.356 \\
.369 \\
.382 \\
.395 \\
.409 \\
.422 \\
.435 \\
.448 \\
.461 \\
.474 \\
.486 \\
.499 \\
.511 \\
.524 \\
.536 \\
.548 \\
.560 \\
.572 \\
.583 \\
.595\end{array}$ & 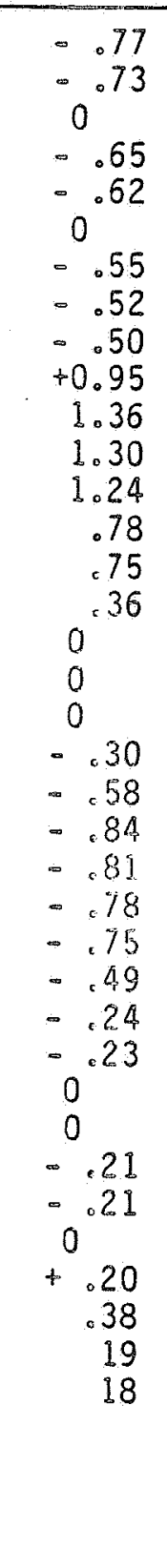 \\
\hline
\end{tabular}




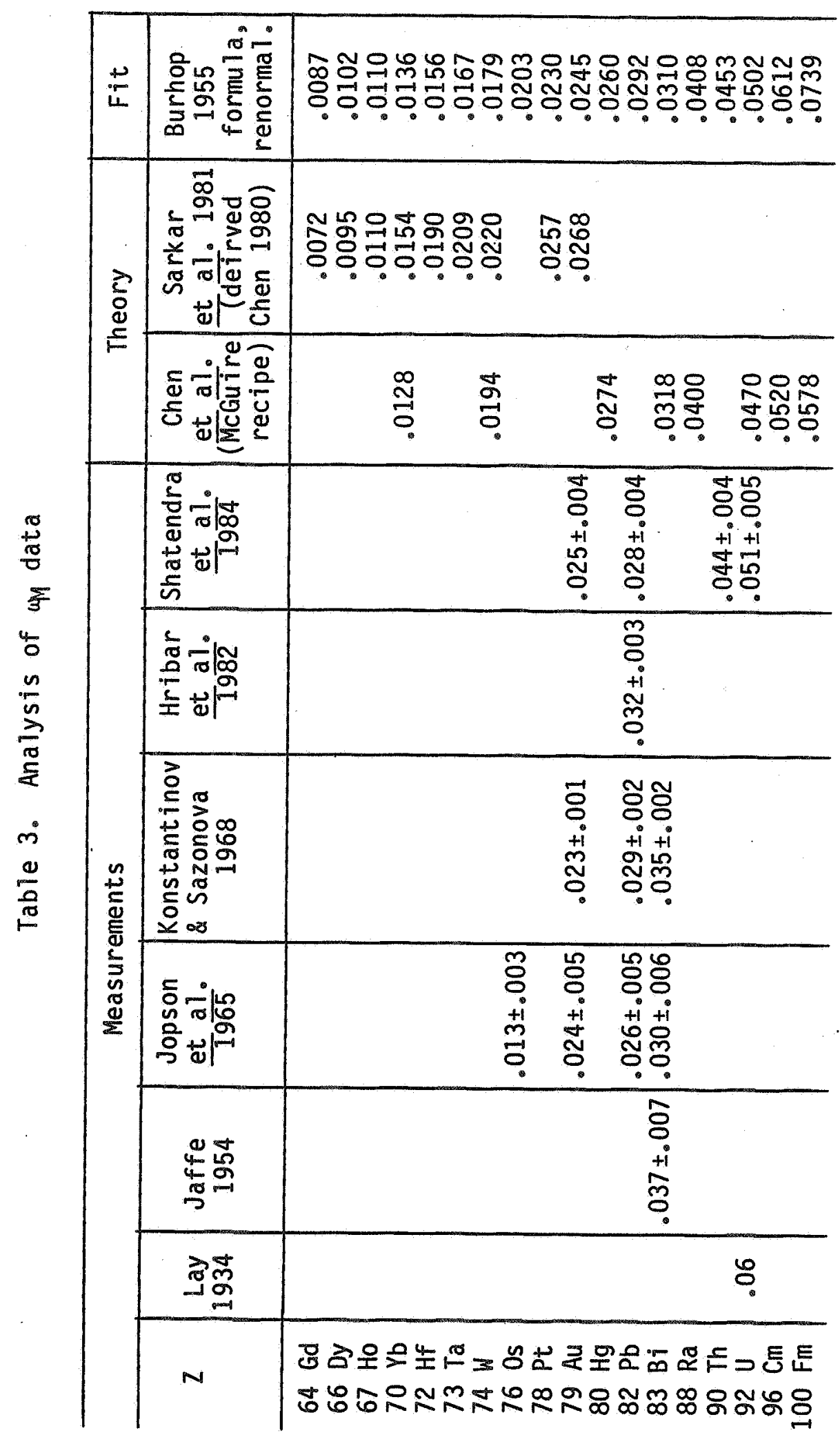


Table 4. Fluorescence yield values $\omega_{K}, \bar{\omega}_{L}$, and $\bar{\omega}_{M}$ for $1 \leqslant Z \leqslant 100$, generated from fitting functions recommended in this report.

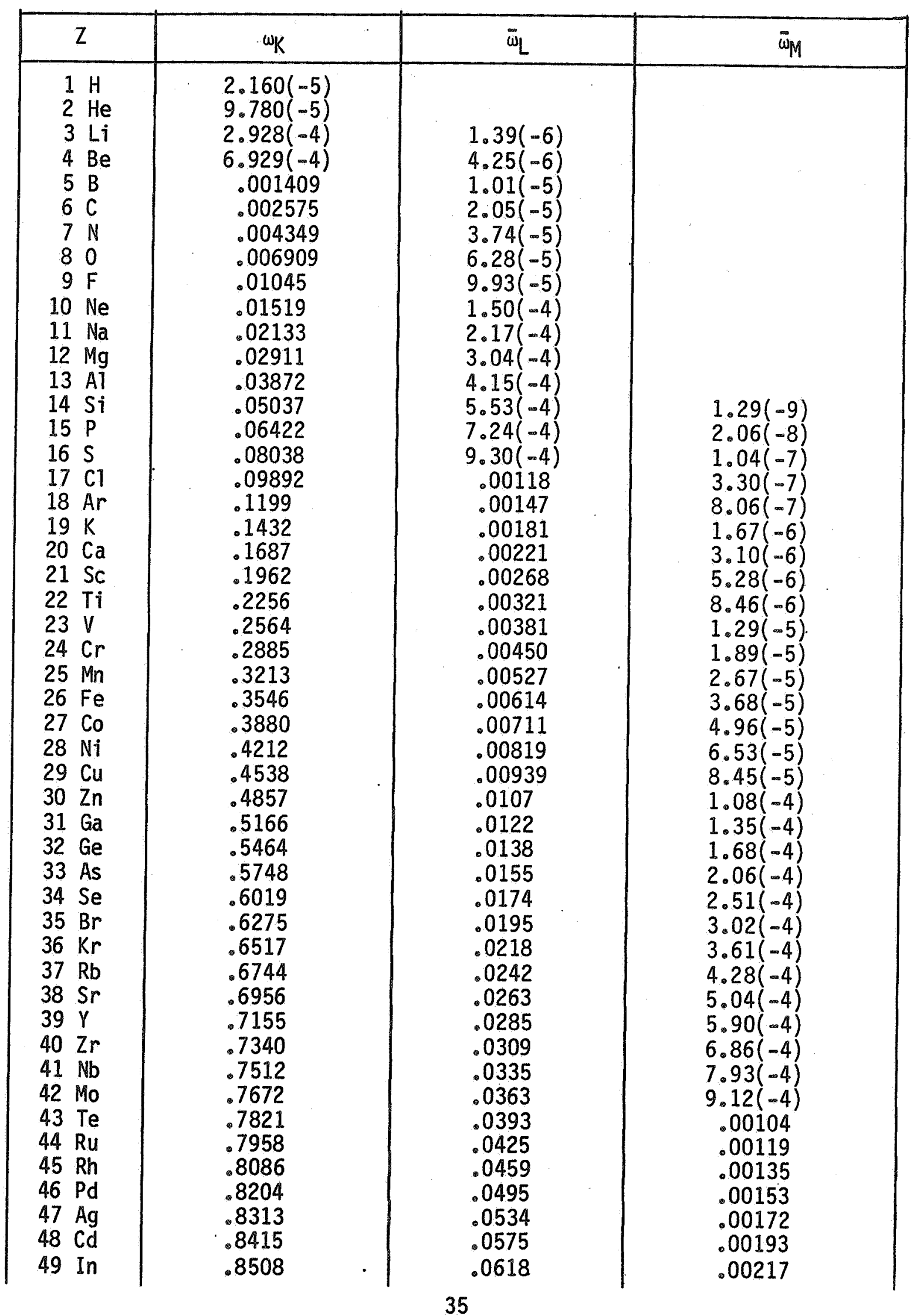


Table 4. Continued

\begin{tabular}{|c|c|c|c|}
\hline$Z$ & $\omega_{K}$ & $\bar{\omega}_{L}$ & $\bar{\omega}_{M}$ \\
\hline $\begin{array}{l}50 \mathrm{Sn} \\
51 \mathrm{Sb} \\
52 \mathrm{Te} \\
53 \mathrm{I} \\
54 \mathrm{Xe} \\
55 \mathrm{Cs} \\
56 \mathrm{Ba} \\
57 \mathrm{La} \\
58 \mathrm{Ce} \\
59 \mathrm{Pr} \\
60 \mathrm{Nd} \\
61 \mathrm{Pm} \\
62 \mathrm{Sm} \\
63 \mathrm{Eu} \\
64 \mathrm{Gd} \\
65 \mathrm{~Tb} \\
66 \mathrm{Dy} \\
67 \mathrm{Ho} \\
68 \mathrm{Er} \\
69 \mathrm{Tm} \\
70 \mathrm{Yb} \\
71 \mathrm{Lu} \\
72 \mathrm{Hf} \\
73 \mathrm{Ta} \\
74 \mathrm{~W} \\
75 \mathrm{Re} \\
76 \mathrm{Os} \\
77 \mathrm{Ir} \\
78 \mathrm{Pt} \\
79 \mathrm{Au} \\
80 \mathrm{Hg} \\
81 \mathrm{Tl} \\
82 \mathrm{~Pb} \\
83 \mathrm{Bi} \\
84 \mathrm{Po} \\
85 \mathrm{At} \\
86 \mathrm{Rn} \\
87 \mathrm{Fr} \\
88 \mathrm{Ra} \\
89 \mathrm{Ac} \\
90 \mathrm{Th} \\
91 \mathrm{~Pa} \\
92 \mathrm{U} \\
93 \mathrm{~Np} \\
94 \mathrm{Pu} \\
95 \mathrm{Am} \\
96 \mathrm{Cm} \\
97 \mathrm{Bk} \\
98 \mathrm{Cf} \\
99 \mathrm{Es} \\
100 \mathrm{Fm}\end{array}$ & 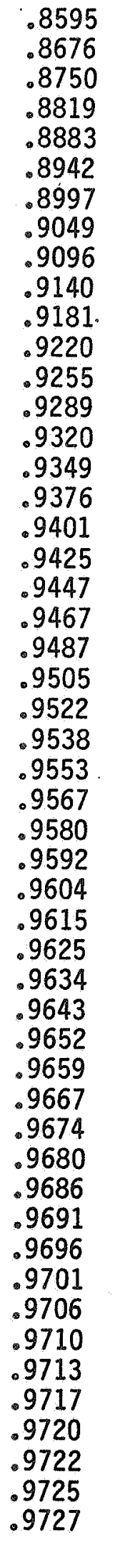 & 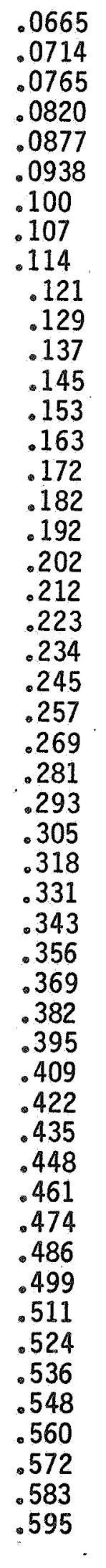 & $\begin{array}{l}.00242 \\
.00269 \\
.00298 \\
.00330 \\
.00365 \\
.00401 \\
.00441 \\
.00484 \\
.00529 \\
.00578 \\
.00629 \\
.00685 \\
.00744 \\
.00806 \\
.00873 \\
.00943 \\
.0102 \\
.0110 \\
.0118 \\
.0127 \\
.0136 \\
.0146 \\
.0156 \\
.0167 \\
.0179 \\
.0191 \\
.0203 \\
.0216 \\
.0230 \\
.0245 \\
.0260 \\
.0275 \\
.0292 \\
.0310 \\
.0328 \\
.0347 \\
.0366 \\
.0387 \\
.0408 \\
.0430 \\
.0453 \\
.0477 \\
.0502 \\
.0528 \\
.0555 \\
.0583 \\
.0612 \\
.0642 \\
.0673 \\
.0706 \\
.0739 \\
\end{array}$ \\
\hline
\end{tabular}


NBS-114A (REY. 2000 )

U.S. DEPT. OF COMM.

BIBLIOGRAPHIC DATA

SHEET (See instructions)

1. PUBLLICATION OR
REPORT NO.
NISTIR $89-4144$

2. Performing Organ. Report No

3. Publication Date

AÜGUST 1989

4. TITLE AND SUBTITLE

BIBLIOGRAPHY AND CURRENT STATUS OF $K$, $L$, AND HIGHER SHELL FLUORESCENCE

YIELDS FOR COMPUTATIONS OF PHOTON ENERGY-ABSORPTION COEFFICIENTS

5. AUTHOR(S)

John H. Hubbel'1

6. PERFORMING ORGANIZATION (If joint or other than NBS, see in structions)

7. Contract/Grant No.

NATIONAL BUREAU OF STANDARDS

7ype of Report \& Period Covered

U.S. DEPARTMENT OF COMMERCE

GATTHERSBURG, MD 20899

9. SPONSORING ORGANIZATION NAME AND COMPLETE ADDRESS (Street, City, Stote, ZIP)

10. SUPPLEMENTARY NOTES

Document describes a computer program; SF.185. FIPS Software. Summary, is attached.

11. ABSTRACT (A 200-word or less factual summary of mose significant information. If document includes a significant bibliography or literature survey. mention it here)

This report reviews $x$-ray fluorescence yield experimental and theoretical information beyond that available in earlier extensive reviews by Fink et al., (1966), Bambynek et al. (1972), and by Krause (1979). An annotated bibliography 1978-1988 is included. Tables and fits of the $K$ shell fluorescence yield $\omega_{K}$, and the average $L$ and $M$ shell fluorescence yields $\bar{\omega}_{L}$ and $\bar{\omega}_{M}$, for use in computing photon energy-absorption coefficients $\mu_{\mathrm{en}} / \rho$, are presented.

12. KEY WORDS (Six to twelve entries: alphabetical order: capitalize only proper names: and separate key words by semicolons) Auger effect; energy-absorption coefficient; fluorescence yield; ionization; photon; radiationless transitions; vacancies; $x$-ray. 13. AVAILABILITY

Unlimited

$\checkmark$ X For Official Distribution. Do Nor Release to NTIS

$\square$ Order From Superincendent of Documents, U.S. Govemment Printing Office, Washington. D.C. 20402.

15. Price

NO, OF

PRINTED PAGES

Order From National Technical Information Sarvice (NTIS), Springfield. VA. 22161 